\begin{abstract}
UNIVERSIDADE DE SÃO PAULO
FFCLRP-DEPARTAMENTO DE FÍSICA

PROGRAMA DE PÓS-GRADUAÇÃO EM CIÊNCIAS

ÁREA DE CONCENTRAÇÃO: FÍSICA APLICADA À MEDICINA E BIOLOGIA
\end{abstract}

WENDER GERALDELLI

\title{
DESENVOLVIMENTO E APLICAÇÃO DE UM SISTEMA DE RAIOS X DISPERSIVO EM ENERGIA PARA DETERMINAÇÃO DO COEFICIENTE DE ATENUAÇÃO LINEAR E DO PERFIL DE ESPALHAMENTO DE NEOPLASIAS MAMÁRIAS
}


WENDER GERALDELLI

\title{
DESENVOLVIMENTO E APLICAÇÃO DE UM SISTEMA DE RAIOS X DISPERSIVO EM ENERGIA PARA DETERMINAÇÃO DO COEFICIENTE DE ATENUAÇÃO LINEAR E DO PERFIL DE ESPALHAMENTO DE NEOPLASIAS MAMÁRIAS
}

\begin{abstract}
Dissertação submetida ao programa de PósGraduação em Física Aplicada a Medicina e Biologia, da Faculdade de Filosofia, Ciências e Letras de Ribeirão Preto, da Universidade de São Paulo, como parte dos requisitos para a obtenção do título de Mestre em Ciências Área de Concentração:
\end{abstract}

Física Aplicada à Medicina e Biologia.

Orientador:

Prof. Dr. Martin Eduardo Poletti

Ribeirão Preto 
Autorizo a reprodução e divulgação total ou parcial deste trabalho, por qualquer meio convencional ou eletrônico, para fins de estudo e pesquisa, desde que citada à fonte.

\section{FICHA CATALOGRÁFICA}

Geraldelli, Wender

Desenvolvimento e aplicação de um sistema de raios $\mathrm{X}$ dispersivo em energia para determinação do coeficiente de atenuação linear e do perfil de espalhamento de neoplasias mamárias. Ribeirão Preto-SP, 2012.

62 p. : il. ; $30 \mathrm{~cm}$

Dissertação de Mestrado, apresentada à Faculdade de Filosofia, Ciências e Letras de Ribeirão Preto/USP. Área de concentração: Física Aplicada à Medicina e Biologia.

Orientador: Poletti, Martin Eduardo

1. Perfil de Espalhamento 2. Coeficiente de atenuação.

3. Neoplasia Mamária. 4. Mamografia

5. Radiodiagnóstico. 


\section{Nome: Geraldelli, Wender}

Título: Desenvolvimento e aplicação de um sistema de raios $\mathrm{X}$ dispersivo em energia para determinação do coeficiente de atenuação linear e do perfil de espalhamento de neoplasias mamárias

Dissertação submetida ao programa de PósGraduação em Física Aplicada a Medicina e Biologia, da Faculdade de Filosofia, Ciências e Letras de Ribeirão Preto, da Universidade de São Paulo, como parte dos requisitos para a obtenção do título de Mestre em Ciências Área de Concentração: Física Aplicada à Medicina e Biologia.

\section{Aprovado em:}

\section{Banca Examinadora}

Prof. Dr. Instituição:

Julgamento: Assinatura:

Prof. Dr. Instituição:

Julgamento: Assinatura:

Prof. Dr. Instituição: Julgamento: Assinatura: 
"Tudo é energia e isso é tudo o que há. Sintonize a realidade que você deseja e inevitavelmente esta é a realidade que você terá. Não tem como ser diferente. Isto não é filosofia. É fisica." (Albert Einstein) 
Dedico este trabalho a:

A meus pais, Ivo e Marley, pais exemplares, que me apoiaram em todas as etapas da vida, e a minha irmã Fabiola, pela compreensão, carinho, presença e incansável apoio ao longo do período de elaboração deste trabalho. 


\section{AGRADECIMENTOS}

A Deus, pela minha vida e pelas oportunidades a mim concedidas.

A meus pais, Ivo e Marley, que sempre me deram suporte para tudo e que nunca me deixaram desistir, que me fizeram acreditar que vale a pena lutar por um sonho, mesmo sabendo da incerteza de realizá-lo e que contribuíram com meu caráter e me transformaram numa pessoa feliz e melhor.

A minha irmã, por fazer parte da minha vida, ser minha melhor amiga e me proporcionar a maior felicidade do mundo.

A minha amiga Fernanda Ferretti por ser companheira em todas as horas. trabalho.

Ao meu orientador, Prof. Martin, pela valiosa orientação em todas as etapas deste

Ao técnico Eldereis de Paula do Departamento de Física (DF) pela ajuda imprescindível no desenvolvimento deste trabalho.

Aos técnicos José Luiz Aziane e Carlos Renato da Silva, da oficina mecânica do DF, pela ajuda na elaboração e construção do arranjo experimental utilizado neste trabalho.

Aos colegas do grupo de Física Radiológica e Dosimetria: Victor, Alex e Marcelo.

A Alessandra Tomal pela experiência e todo conhecimento compartilhado ao longo do curso.

Aos professores do curso de pós-graduação em Física Aplicada à Medicina e Biologia, do Departamento de Física e Matemática da Faculdade de Filosofia Ciências e Letras de Ribeirão Preto, que contribuíram para minha formação.

Às secretárias do Departamento Física, em especial à Nilza, secretária do programa de pós-graduação em Física Aplicada à Medicina e Biologia por todo suporte durante o período de pós-graduação.

A CAPES, pelo apoio que permitiu a realização do meu mestrado.

A todos que, de alguma forma, contribuíram direta ou indiretamente para este trabalho. 


\section{RESUMO}

Geraldelli, W. Desenvolvimento e Aplicação de um sistema de raios X Dispersivo em Energia para Determinação do Coeficiente de Atenuação Linear e do Perfil de Espalhamento de Neoplasias Mamárias. (Dissertação). Ribeirão Preto: Faculdade de Filosofia Ciências e Letras de Ribeirão Preto, Universidade de São Paulo; 2012.

As propriedades de espalhamento de raios $\mathrm{X}$ e atenuação de tecidos mamários normais (adiposo e fibroglandular), neoplásicos (benigno e maligno) e vários materiais tecido-equivalente (nylon, poliacetato, polimetilmetacrilato (PMMA), água, músculo-equivalente, osso-equivalente e adiposo-equivalente) foram determinados usando um sistema de raios X dispersivo em energia (SRXDE). O SRXDE consistiu de um tubo de raios $\mathrm{X}$ com anodo de tungstênio operando a $60 \mathrm{kVp}$, um goniômetro e dois detectores: um detector de telureto de cádmio (CdTe), posicionado a 7 graus com relação ao feixe incidente usado para detectar a distribuição em energia dos fótons espalhados (numa faixa de momento transferido de $0,5 \mathrm{~nm}^{-1}$ $-3,5 \mathrm{~nm}^{-1}$ ) e um detector de silício (Silicon Drift Detector, SDD), posicionado a zero graus e usado para detectar a distribuição em energia do feixe transmitido (com amostra) ou do feixe incidente (sem amostra). A distribuição espectral foi processada para se obter o perfil de espalhamento e o coeficiente de atenuação linear de 100 amostras de tecidos mamários (59 normal, 30 maligno e 11 benigno). Este sistema foi, também, aplicado ao estudo de regiões de transição entre tecidos com diferentes composições. Os resultados encontrados neste trabalho mostram que os tecidos mamários podem ser caracterizados através de suas propriedades de atenuação e espalhamento. Perfis de espalhamento neoplásico apresentam formato do pico principal significativamente diferente na faixa de momento transferido de $0,8 \mathrm{~nm}^{-1}-2,0 \mathrm{~nm}^{-1}$, aos tecidos normais. Especificamente, o tecido adiposo apresentou um perfil de espalhamento muito diferente (pico principal em $1,12 \mathrm{~nm}^{-1}$ e LMA de $0,33 \mathrm{~nm}^{-1}$ ) quando comparado com tecidos neoplásico maligno e benigno e normal fibroglandular (pico principal em torno de $1,54 \mathrm{~nm}^{-1}$ e LMA em torno de $0,73 \mathrm{~nm}^{-1}$ ).

O coeficiente de atenuação linear observado para os tecidos maligno, benigno e fibroglandular são muito similares e mostraram diferenças menores que $8 \%$ para energias entre 10 e $35 \mathrm{keV}$. Entretanto, o tecido adiposo apresentou diferenças significativas com relação aos outros tecidos em toda faixa de energia (diferenças de até $40 \%$ foram observadas).

Os resultados obtidos da varredura espacial das amostras heterogêneas mostram que o sistema desenvolvido permite o estudo de regiões de transição entre tecidos com diferentes composições.

Finalmente, nossos resultados foram comparados com dados experimentais previamente publicados na literatura, mostrando boa concordância dentro das incertezas estatísticas.

Palavras-chaves: Câncer de mama, Perfil de Espalhamento de raios X, Coeficiente de Atenuação, Mamografia. 


\begin{abstract}
Geraldelli, W. Development and Application of an Energy Dispersive X-ray System for Determining the Linear Attenuation Coefficient and Scattering Profile of Breast Diseases. (Dissertation). Ribeirão Preto: Faculdade de Filosofia Ciências e Letras de Ribeirão Preto, Universidade de São Paulo; 2012.
\end{abstract}

The X-ray scattering and attenuation properties for normal (adipose and glandular) and neoplastic (benign and malignant) breast tissues and several tissue-equivalent materials (nylon, polyacetate, polymethylmethacrylate (PMMA), water, muscle-equivalent, bone-equivalent and adipose-equivalent) were determined using an energy dispersive X-ray system (EDXS). The EDXS consisted of a tungsten anode X-ray tube operating at $60 \mathrm{kVp}$, a goniometer, and two detectors: a Cadmium Telluride (CdTe) detector, positioned at 7 degrees with relation to the incident beam used for detecting the energy distribution of scattered photons (over the momentum transfer range of $0,5 \mathrm{~nm}^{-1}-3,5 \mathrm{~nm}^{-1}$ ) and a Silicon Drift Detector (SSD), positioned at zero degree used for detecting the energy distribution of the transmitted beam (with the sample) or the incident beam (without the sample). The spectra distributions were processed to obtaine the scattering profile and the linear attenuation coefficient of 100 samples of breast tissues (59 normal, 30 malignant and 11 benign). This system was also applied to the study of the transition regions between tissues with different composition.

The results found in this work show that breast tissues may be characterized through their attenuation and scattering properties. Neoplastic scattering profiles presented format and the main peak position significantly different in the range of momentum transfer from $0,8 \mathrm{~nm}^{-1}-2,0 \mathrm{~nm}^{-1}$, to normal tissues. Specifically, adipose tissue presented a very different scattering profile (main peak at $1,12 \mathrm{~nm}^{-1}$ and FWHM of $0,33 \mathrm{~nm}^{-1}$ ) when compared with malignant, benign and also normal glandular tissues (main peak around $1,54 \mathrm{~nm}^{-1}$ and FWHM about of $0,73 \mathrm{~nm}^{-1}$ ).

The linear attenuation coefficient observed for malignant, benign and normal glandular tissues were quite similar and showed differences smaller than $8 \%$ for energies between 10 and $35 \mathrm{keV}$. However, adipose tissue presented significant differences from the others tissues type in all energy range (differences up to $40 \%$ were observed).

The results of the spatial scan of heterogeneous samples show that the developed system allows the study of transition regions between tissues with different composition.

Finally, our results were compared with previous experimental data showing a good agreement within the experimental uncertainties.

Keywords: Breast cancer, X-ray Scattering Profile, Attenuation Coefficient, Mammography. 


\section{LISTA DE FIGURAS}

Figura 2.1: Estrutura anatômica da mama (Patrick J. Lynch.) ....................................................................................

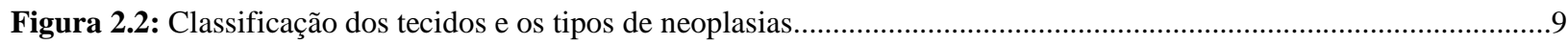

Figura 2.3: Espectro eletromagnético (http://bussoladeplasma.wordpress.com/tag/ondas/).............................................11

Figura 2.4: Exemplificação de um tubo de raios $X$ com anodo de tungstênio (W) e seu respectivo espectro....................12

Figura 2.5: Representação esquemática do efeito fotoelétrico...................................................................................13

Figura 2.6: Representação esquemática do espalhamento incoerente..............................................................................14

Figura 3.1: Classificação histológica das amostras utilizadas neste trabalho, bem como a quantidade de amostras em cada classe de classificação..

Figura 3.2: Porta-amostra utilizado na medida do perfil de espalhamento e coeficiente de atenuação linear das amostras de

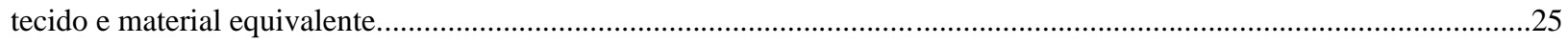

Figura 3.3: Arranjo experimental para medição das propriedades de atenuação e espalhamento.....................................26

Figura 3.4: Curva de Calibração dos detectores. (a) CdTe e (b) SDD .....................................................................28

Figura 3.5: Relação da eficiência em função da energia para o detector Silicon Drift Detector (SDD) e para o detector de

Telureto de Cádmio (CdTe) (Tomal, et al. 2012)......................................................................................................29

Figura 3.6: Comparação entre as seções de choque para diferentes ângulos de coleta do feixe espalhado........................31

Figura 3.7: Comparação entre os espectros medidos pelo detector de CdTe a uma distância de 70mm e 110mm da

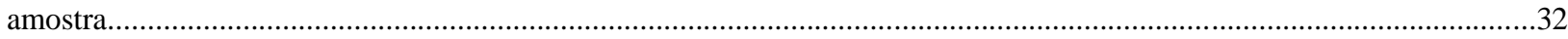

Figura 3.8: Esquema experimental do SRXDE e em destaque a região irradiada na amostra.........................................33

Figura 3.9: Resolução em momento transferido, $\Delta x$, em função do momento transferido $x$............................................34

Figura 3.10: (a) Seções de choque diferenciais coerente e incoerente em função do momento transferido calculado a partir dos dados para tecido muscular de Kosanezky et al. 1987. (b) Razão da seção de choque diferencial coerente pela seção de choque diferencial incoerente em função do momento transferido................................................................................35

Figura 3.11: Validação do método através da comparação do coeficiente de atenuação linear do poliacetato com os

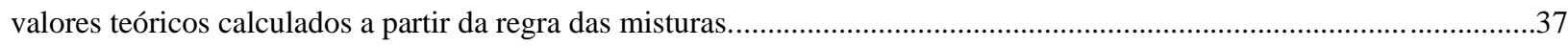

Figura 3.12: Comparação entre os perfis de espalhamento normalizados obtidos experimentalmente com os dados

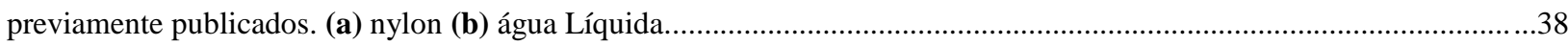

Figura 4.1: Comparação entre o coeficiente de atenuação linear do material tecido-equivalente determinado experimentalmente, e o tecido correspondente obtido teoricamente: (a) adiposo, (b) múscular e (c) ósseo...

Figura 4.2: Comparação entre os resultados obtidos para o coeficiente de atenuação linear dos tecidos mamários e resultados previamente publicados na literatura: (a) adiposo, (b) fibroglandular, (c) carcinoma e (d) fibroadenoma..........42

Figura 4.3: Comparação entre os resultados do coeficiente de atenuação linear do tecido normal fibroglandular e tecidos neoplásicos (fibroadenoma e carcinoma).

Figura 4.4: Comparação entre o perfil de espalhamento dos materiais tecido- equivalente e dos tecidos humanos. (a) adiposo-equivalente e tecido adiposo. (b) Água e tecido muscular. (c) osso-equivalente e tecido ósseo (Geraldelli et al. 2012)...

Figura 4.5: Comparação entre os perfis de espalhamento médio, máximo e mínimo para os tecidos analisados neste trabalho e os correspondentes dados previamente publicados na literatura. (a) adiposo (b) fibroglandular (c) carcinoma (d) fibroadenoma.

Figura 4.6: Imagem de uma amostra heterogênea de tecido mamário composto por tecido adiposo e fibroglandular. Os pontos A, B e C representados são os locais aproximados onde incidiu a radiação durante as medições.

Figura 4.7: Comparação dos coeficientes de atenuação linear e dos perfis de espalhamento entre os três pontos estudados durante o processo de varredura de uma amostra heterogênea de tecido mamário composta por tecido adiposo e fibroglandular.

Figura 4.8: Resultados médios para o coeficiente de atenuação linear e perfil de espalhamento para cada tipo de tecido. (a) coeficiente de atenuação linear. (b) perfil de espalhamento... 


\section{LISTA DE TABELAS}

Tabela 3.1: Materiais tecido-equivalentes - Densidades e Composição

Tabela 3.2: Valores das variáveis independentes para a construção da geometria utilizada neste trabalho. 33

Tabela 3.3: Tecidos humano - Densidades e Composição.........................................................................39

Tabela 4.1: Comparação da posição do pico principal, segundo pico e largura a meia altura (LMA) para os tecidos muscular e ósseo, água e osso-equivalente.

Tabela 4.2: Comparação dos parâmetros posição do pico principal, intensidade e largura a meia altura entre os perfis de espalhamentos obtidos neste trabalho e outros previamente publicados. 


\section{LISTA DE ABREVIATURAS E SIGLAS}

PMMA: Polimetilmetacrilato

PVC: Policloreto de vinila

ICRU: International Commission on Radiation Units

LMA: Largura a meia altura

OMS: Organização Mundial da Saúde

SAXS: Small Angle X-ray Scattering (Espalhamento de raios X em baixos ângulos)

WAXS: Wide Angle X-ray Scattering (Espalhamento de raios X em médios ângulos)

MAI: Modelo Atômico Independente

$x$ : Momento transferido

SRXDE: Sistema de raios X Dispersivo em Energia

SDD: Silicon Drift Detector

CdTe: Telureto de Cádmio

$\mu(E)$ : Coeficiente de atenuação linear

$I_{0}(E)$ : Contagem de fótons com energia $\mathrm{E}$ no espectro incidente

$I_{t}(E)$ : Contagem de fótons com energia $\mathrm{E}$ no espectro atenuado

$\mu_{a r}:$ Coeficiente de atenuação linear para o ar

$N(E)_{D}^{C d T e}$ : Distribuição de energia do número de fótons espalhados detectados

$N(E)_{S}^{c o r r}$ : Distribuição de energia da contribuição do espalhamento simples

$B(E)$ : Medida do sinal de background

$T(E)$ : Fator de transmissão

$\eta_{v}$ : Número de átomos ou moléculas por unidade de massa

$d \sigma_{T h} / d \Omega$ : Seção de choque Thomson

$F(x)$ : Fator de forma

$G(E)$ : Fator de transmissão geométrico 
$\varepsilon(E)_{S D D}$ : Eficiência do detector SDD

$\varepsilon(E)_{C d T e}$ : Eficiência do detector CdTe

$\mu(E) / \rho$ : Coeficiente de atenuação mássico

$d \sigma_{T h} / d \Omega$ : Seção de choque Rayleigh 


\section{Conteúdo}

CAPÍTULO 1.

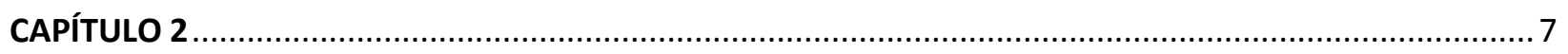

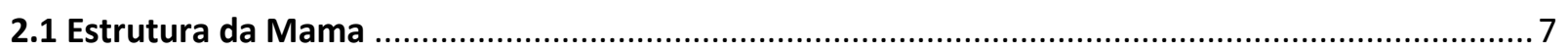

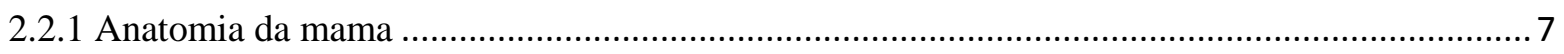

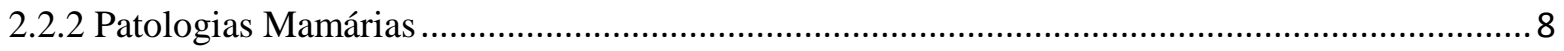

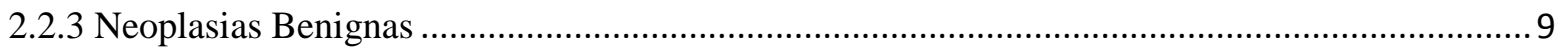

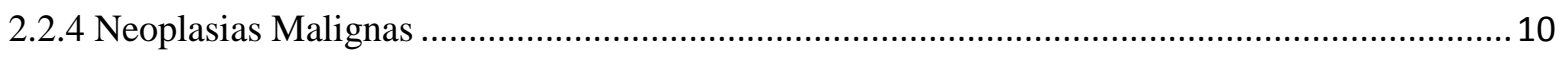

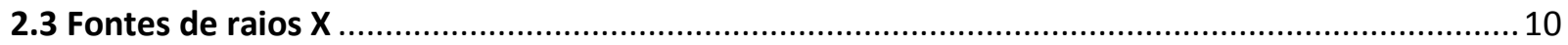

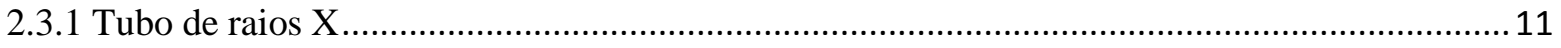

2.4 Interação da Radiação com a Matéria ................................................................................ 12

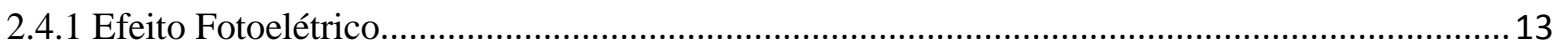

2.4.2 Espalhamento Inelástico …............................................................................................. 14

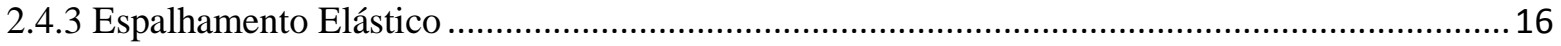

2.4.4 O espalhamento no Radiodiagnóstico ............................................................................... 19

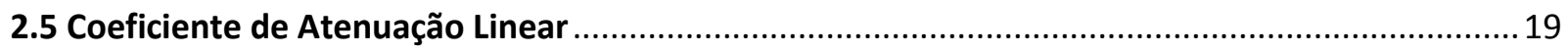

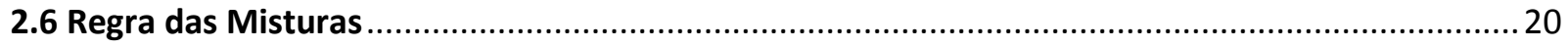

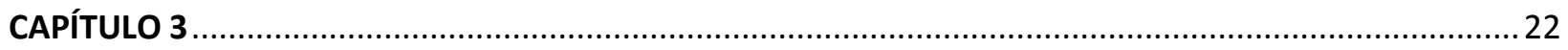

3.1 Amostras de tecidos biológicos e materiais tecido-equivalente .............................................22

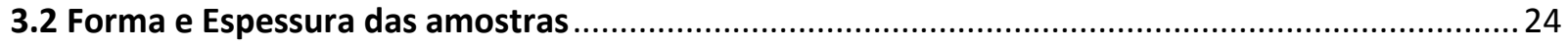

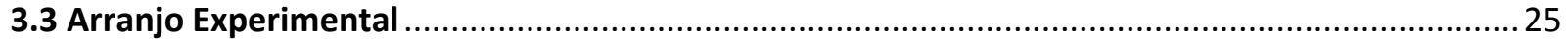

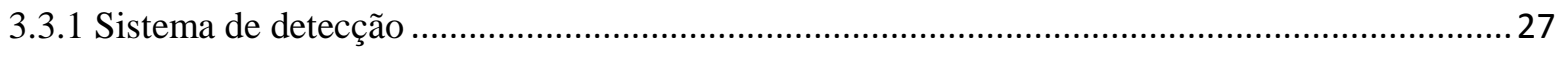

3.3.2 Otimização do Arranjo Experimental ................................................................................ 29

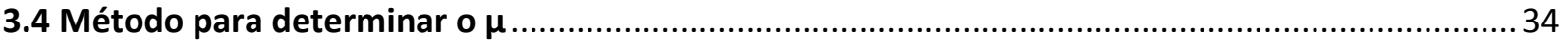

3.5 Método para determinar o perfil de espalhamento ................................................................... 34

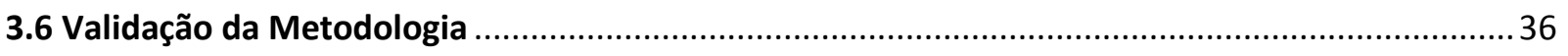

3.7 Escolha do melhor material tecido-equivalente .................................................................. 38

CAPÍTULO 4

4.1 Propriedades de atenuação de materiais tecido-equivalentes ................................................ 40

4.2 Propriedades de atenuação dos tecidos humanos ................................................................... 41

4.3 Propriedades de espalhamento dos materiais tecido-equivalentes........................................... 44

4.4 Propriedades de espalhamento dos tecidos mamários humano ............................................... 46 
4.5 Potencialidades do Sistema de raios X Dispersivo em Energia ................................................50

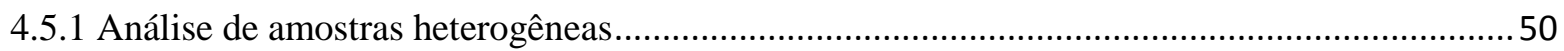

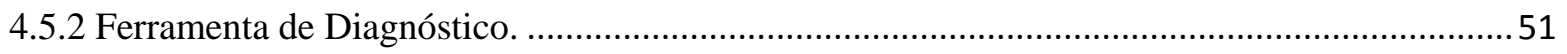

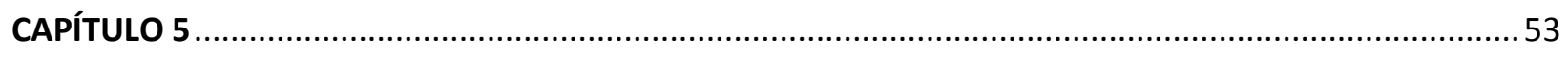

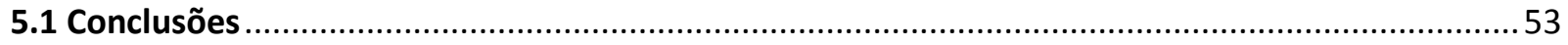

5.1.1 Sobre o método de medição simultânea das propriedades de atenuação e espalhamento dos

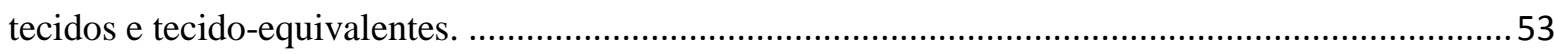

5.1.2 Sobre os resultados obtidos para os materiais tecido-equivalentes quanto suas propriedades de

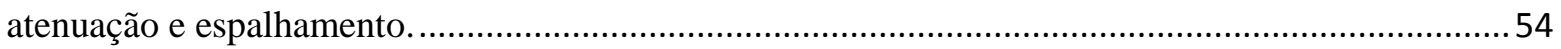

5.1.3 Sobre os resultados obtidos para os tecidos mamários humanos quanto suas propriedades de

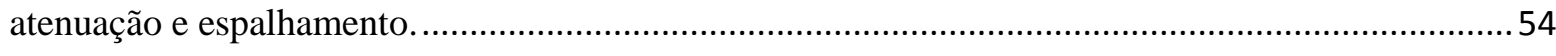

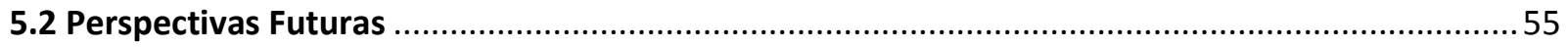

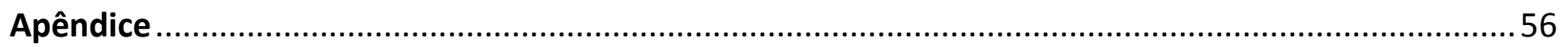

A - Aprovação do Comitê de Ética em Pesquisa ...........................................................................56

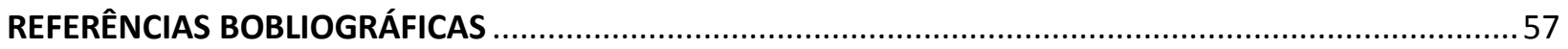




\section{CAPÍTULO 1}

\section{INTRODUÇÃO}

O câncer de mama é o segundo tipo de câncer mais comum no mundo, sendo o de maior incidência entre as mulheres (Stewart; Kleihues, 2003). A cada ano, entorno de 23\% dos casos de câncer em mulheres são de mama (INCA, 2011). Além disso, é responsável por cerca de $20 \%$ de todas as mortes devido ao câncer. Mantendo-se esta tendência, até 2015 cerca de 83,2 milhões de mulheres deverão vir a óbito (Organização Mundial da Saúde, OMS). Todavia, se o câncer de mama é diagnosticado e tratado em sua fase inicial, aproximadamente $90 \%$ dos pacientes podem ser curados (Seidman et al. 1982, Michaelson et al. 2002).

A detecção precoce do câncer de mama é fundamental para o combate à doença, possibilitando a utilização de tratamentos menos agressivos e aumentando as chances de cura dos pacientes. Várias são as técnicas utilizadas para detecção do câncer de mama, sendo o exame clínico e a mamografia as principais delas, podendo ser complementadas por exames de ultra-sonografia, cintilografia, ressonância magnética e por diversas técnicas de biópsia (punção aspirativa por agulha fina, biopsia de fragmento e mamotomia) (Mautner; Schimidt; Brennan, 2000).

Atualmente, a técnica mais adequada no auxílio à detecção precoce do câncer de mama é a mamografia (Tabar et al. 1985). Entretanto, a mamografia não permite o diagnóstico, ou seja, a caracterização específica de uma anomalia como maligna ou benigna, atuando apenas na identificação da presença dessa anomalia, sendo necessária uma biópsia para o diagnóstico definitivo. Devido a limitações inerentes a essa técnica, alguns diagnósticos falso-positivo e falso-negativo acontecem, resultando em casos de câncer não diagnosticados ou biópsias desnecessárias, respectivamente (Mushlin et al. 1998, Souhami e Tobias, 1998). Este fato ocorre principalmente, devido à pequena diferença nas propriedades de atenuação dos tecidos mamários e à ocorrência de efeitos de espalhamento (inelástico e elástico), fatores esses que 
degradam o contraste da imagem, diminuindo a eficácia de detecção desse exame (Koch et al. 1996; Barnes, 1991, Poletti, 1997). No intervalo de energia usado em mamografia, 50\% da radiação transmitida pela mama é devido aos fótons espalhados (Cunha et al. 2010). Dessa forma, surgiram muitos estudos a respeito das propriedades de atenuação e espalhamento dos tecidos humanos.

White et al. (1980) mediu o coeficiente de atenuação linear de tecidos mamários normais sem classificação histológica. Utilizou um detector semicondutor de HPGe e raios X fluorescentes. Johns e Yaffe (1987) caracterizaram as propriedades de atenuação de tecidos mamários normais (adiposos e glandulares) e carcinomas, utilizando um feixe de raios $\mathrm{X}$ polienergético com energias entre $18 \mathrm{keV}$ e $120 \mathrm{keV}$, e um detector de HPGe. Carroll et al. (1994) mediram o coeficiente de atenuação linear de tecidos mamários normais (adiposos e glandulares) e neoplásicos, usando um feixe de raios $\mathrm{X}$ monoenergético produzido por uma fonte síncroton no intervalo de 14 e $18 \mathrm{keV}$. Al-Bahri e Spyrou (1996) usaram raios gama com energia de $59,54 \mathrm{keV}$ para determinar o coeficiente de atenuação linear dos tecidos normais (adiposos e glandulares) e neoplásicos provenientes do mesmo paciente. Baldazzi et al. (2008) determinaram o coeficiente de atenuação linear de tecidos mamários neoplásicos, na faixa de energia de 10 a 55keV, usando um feixe de raios $\mathrm{X}$ polienergético. Tomal et al. (2010) mediram os coeficientes de atenuação linear de tecidos mamários normais (adiposos e glandulares) e neoplásicos (malignos e benignos), usando um feixe de raios $\mathrm{X}$ monoenergéticos com energia entre 8 e 30keV.

Por outro lado, Kosanetzky et al. (1987) utilizaram um difratômetro de raios X com anodo de Co $\left(\mathrm{K}_{\alpha}=6,935 \mathrm{keV}\right)$ e mediram os perfis de espalhamento da água, materiais tecido-equivalentes e tecidos biológicos extraídos de animais (adiposo, músculo, entre outros). Evans et al. (1991) mediram os perfis de espalhamento de tecidos mamários (adiposos, fibroglandular, carcinoma e fibroadenoma), utilizando um feixe de raios $\mathrm{X}$ polienergético produzido por um tubo de raios $\mathrm{X}$ com anodo de cobre, operando a $60 \mathrm{kVp}$ (energia média efetiva de $46 \mathrm{keV}$ ). Tartari et al. (1997) mediram a seção de choque diferencial de espalhamento elástico de gordura provenientes de suínos e PMMA, utilizando um tubo de raios X com um anodo de cobre $\left(\mathrm{K}_{\alpha}=8,04 \mathrm{keV}\right)$. Peplow e Verghese (1998) tabularam o fator de forma molecular de espalhamento elástico de materiais plásticos, tecidos biológicos de animais e mamário humano. 
Utilizando radiação síncroton monoenergética de $8 \mathrm{keV}$ e $20 \mathrm{keV}$. Kidane et al. (1999) mediram o perfil de espalhamento para tecido mamários normais e neoplásicos através da técnica de espalhamento de raios $\mathrm{X}$ dispersivo em energia, usando um tubo de raios $\mathrm{X}$ com anodo tungstênio, operando em $80 \mathrm{kVp}$. $\left(\mathrm{K}_{\alpha}=58,86 \mathrm{keV}\right)$. Poletti et al. (2002a) mediram o coeficiente de espalhamento elástico de tecidos mamários normais e neoplásicos utilizando tubos de raios $\mathrm{X}$ com anodo de cobalto $\left(\mathrm{K}_{\alpha}=6,93 \mathrm{keV}\right)$ e molibdênio $\left(\mathrm{K}_{\alpha}=17,44 \mathrm{keV}\right)$. Castro et al. (2005) obtiveram os perfis de espalhamento elástico para tecidos mamários humanos normais e neoplásicos, útero e rim, usando radiação síncroton. Changizi et al. (2005) utilizaram a técnica de SAXS (espalhamento de raios $\mathrm{X}$ em baixos ângulos) para diferenciar tecido mamário normal e neoplásico. Eles analisaram tecido normal adiposo, normal heterogêneo (adiposo mais fibroglandular) e tecido neoplásico, observando que os picos de espalhamento ocorriam em diferentes posições, sendo possível diferenciar esses tecidos. Ainda notaram que a diferenciação entre tecido normal e neoplásico também poderia ser feita pela intensidade do pico do perfil de espalhamento. Eles também observaram que os resultados eram reproduzíveis mesmo quando os tecidos eram armazenados previamente em nitrogênio líquido. Cunha et al. (2006) utilizaram feixe de raios X monoenergético de $8,04 \mathrm{keV}$ gerado por um tubo de raios $\mathrm{X}$ com anôdo de cobre e um detector cintilador de NaI(TI) para medir os perfis de espalhamento de tecidos mamários normais e neoplásicos maligno. Nestes perfis de espalhamento medidos, eles aplicaram análise discriminante e conseguiram classificar corretamente $97 \%$ das amostras analisadas. Griffiths et al. (2007) correlacionaram imagens por difração e transmissão usando a técnica de microCT para 19 amostras e mostraram que a razão entre as intensidades de dois picos característicos em tecidos mamários, sendo em 13,8 e 18,9nm $\mathrm{nm}^{-1}$ (definido como $q=4 \pi x$, onde $x=$ $\left.\lambda^{-1} \operatorname{sen}(\theta / 2)\right)$, pode ser utilizada para caracterizar cada tipo de tecido. Oliveira et al. (2008) apresentaram perfis de espalhamento de amostras histopatologicamente classificadas como tecido normal, neoplasia benigna e maligna, obtidas com um difratômetro comercial, bem como descreveram os procedimentos para corrigir tais perfis medidos. Além disso, nesses perfis corrigidos foi aplicada análise multivariada, mostrando que esta análise possui uma sensibilidade de $96 \%$ e uma especificidade de $82 \%$ na distinção entre tecido normal e neoplásico. Conceição (2008) usando radiação síncroton 
monocromática de $8,4 \mathrm{keV}$, combinaram simultaneamente as técnicas de WAXS (espalhamento de raios X em médios ângulos) e SAXS sob um mesmo conjunto de amostras de tecidos mamários normais e neoplásicos para obter os perfis de espalhamento dessas amostras. Eles extraíram desses perfis dois

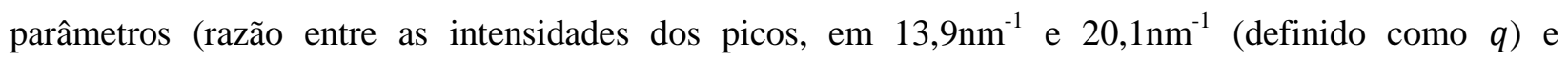
intensidade do pico de $3^{\mathrm{a}}$ ordem de reflexão das fibras de colágeno) e verificaram que a combinação destes parâmetros pode ser utilizada para identificação do câncer de mama. Chaparian et al. (2010) desenharam e avaliaram um sistema de difração de raios X dispersivo em energia para aplicação clínica. Eles estudaram a relação entre vários parâmetros do arranjo experimental (sensibilidade, resolução espacial e resolução em momento transferido). Determinaram os parâmetros ótimos através de perfis de espalhamento de tecidos mamários utilizando um tempo de aquisição eficiente. Pani et al. (2010) utilizaram um sistema de raios $\mathrm{X}$ dispersivo em energia de tomografia computadorizada para caracterização de tecido mamário. Eles compararam os perfis de espalhamento dos tecidos com sua classificação histológica e determinaram a possibilidade de dividir os tipos de tecidos em cinco famílias: adiposo, fibroso, câncer pobremente diferenciado, câncer altamente diferenciado e tumor benigno. Elshemey et al. (2010) utilizaram os parâmetros largura a meia altura (LMA) e área sob o perfil de espalhamento em $1,6 \mathrm{~nm}^{-1}$ e $1,1 \mathrm{~nm}^{-1}$ (definido como $x$ ) que correspondem ao espalhamento de tecidos moles e adiposo, respectivamente, com o intuito de detectar alterações nas amostras de tecidos estudadas. O conceito de considerar o espalhamento como uma desvantagem vem mudando ultimamente, devido a dois fatores importantes (Speller, 1999, Kidane et al. 1999, Poletti et al. 2002a, 2002b): (i) os fótons espalhados carregam informação sobre a estrutura dos tecidos do paciente, informação que não é obtida na radiografia convencional, (ii) na maioria das energias usadas nas aplicações médicas, a interação mais provável é o espalhamento (elástico + inelástico). Estes fatos conduziram às pesquisas sobre as propriedades de espalhamento dos diferentes tecidos biológicos, tornando-se necessário à obtenção de medidas precisas dos perfis de espalhamento dos diferentes tecidos humanos (Poletti et al. 2002b). 
Dessa forma como as estruturas dos vários tecidos que compõem a mama são distintas, as informações trazidas pela radiação espalhada podem ser úteis na diferenciação entre um tecido normal e um alterado, ou ainda, entre tecidos alterados (benignos e malignos).

Além disso, é valioso mencionar que embora existam trabalhos publicados na literatura referentes às propriedades de atenuação e espalhamento dos tecidos humanos, não há trabalhos disponíveis que apliquem simultaneamente a determinação destas propriedades em um mesmo conjunto de amostras de tecidos mamários para diferenciação e caracterização. O que representa uma lacuna importante para aplicação dos trabalhos anteriormente referenciados.

Dessa forma, este trabalho, tem como objetivos:

- Construir um protótipo experimental que possibilite a medição simultânea das propriedades de atenuação e espalhamento das diferentes amostras de tecidos mamário humano e materiais tecidoequivalente.

- Explorar a utilidade e potencial da análise simultânea das propriedades de atenuação e espalhamento para um mesmo conjunto de amostras.

Esta dissertação foi organizada da seguinte forma:

No capitulo 2, é apresentado uma descrição das estruturas da mama, bem como as principais patologias mamárias. Além de um breve resumo das fontes de radiação utilizada neste trabalho, dos fundamentos teóricos em que este trabalho está baseado e dos principais processos de interação da radiação com a matéria.

O capítulo 3 descreve os tecidos mamários e os materiais tecido-equivalente analisados, bem como o arranjo experimental construído para possibilitar a medição simultânea das propriedades de atenuação e espalhamento das amostras. Além disso, é apresentado a otimização do arranjo experimental.

O capítulo 4 apresenta os resultados obtidos. Primeiramente são mostrados os resultados para os materiais tecido-equivalente e posteriormente os resultados para os tecidos mamários humano. Ainda mostra os resultados obtidos através de uma varredura espacial de uma amostra heterogênea. 
O capítulo 5 é dedicado às conclusões sobre os métodos utilizados, os resultados obtidos, bem como as perspectivas para trabalhos futuros. 


\section{CAPÍTULO 2}

\section{FUNDAMENTOS TEÓRICOS}

\subsection{Estrutura da Mama}

Para a perfeita compreensão dos processos patológicos de um órgão, é necessário conhecer sua estrutura e função. Nesta seção serão apresentadas as estruturas anatômicas e fisiológicas de uma mama normal. Posteriormente serão estudadas as principais patologias da mama, classificadas em neoplasias benignas e malignas.

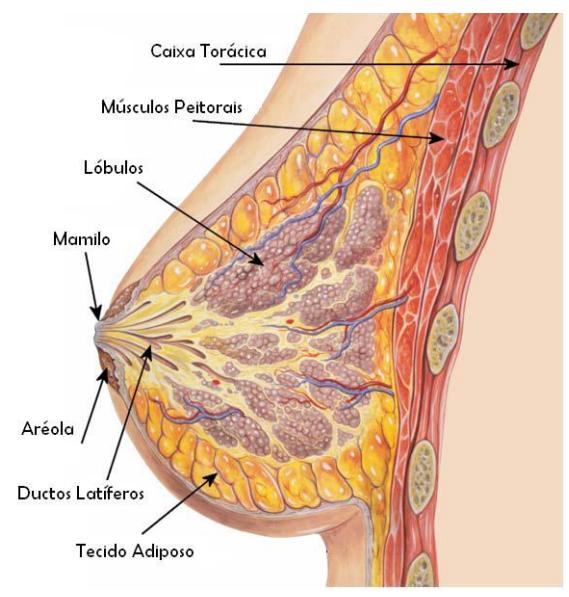

Figura 2.1: Estrutura anatômica da mama (Patrick J. Lynch).

\subsubsection{Anatomia da mama}

A estrutura anatômica da mama é mostrada na figura 2.1 e, pode ser dividida em duas componentes: estrutural e funcional (Dângelo e Fattini, 2003, Netter, 2004).

E como resumido por Conceição (2008), a componente estrutural é responsável pela sustentação e proteção das estruturas da mama, denominado estroma mamário. O estroma mamário por sua vez é dividido em estroma interlobular e intralobular. O estroma interlobular, na mulher jovem, é composto basicamente de tecido conjuntivo denso (fibroso), contando ainda com algumas células de tecido adiposo (adipócitos). Já o estroma intralobular possui grande quantidade de tecido conjuntivo frouxo e uma 
pequena população de células de linfócitos, além de ser muito sensível às variações hormonais do ciclo menstrual. A constituição do estroma mamário é variável, devido ao fato de que com o passar dos anos é aumentada a quantidade de tecido adiposo e, consequentemente diminui a proporção de tecido conjuntivo. Por sua vez, a componente funcional é responsável pelas principais funções da mama, como produzir e secretar o leite, e é denominado parênquima mamário. O parênquima mamário é composto basicamente por células epiteliais. As mamas são consideradas anexas à pele, uma vez que as glândulas cutâneas se modificaram e deram origem às glândulas mamárias ou unidades lobulares. Cada glândula mamária é composta de 15 a 20 lóbulos. Os lóbulos mamários são estruturas de contorno circular, formados pelo agrupamento de ácinos e ductos e circundados pelo estroma interlobular. Os ácinos têm a função de secretar o leite e são compostos por dois tipos de células: uma camada interna de células epiteliais e uma camada externa de células mioepiteliais. A função das células mioepiteliais é a de se contrair para promover a extrusão do leite secretado. Os ductos mamários, como os ácinos, são formados por uma dupla população de células de revestimento, epiteliais (interno) e mioepiteliais (externo), possuindo grande quantidade de água em sua composição, cuja principal função é drenar os lóbulos.

A distribuição dos tecidos conjuntivo denso e frouxo, epitelial e adiposo, depende de fatores como: ciclo hormonal, idade, alimentação e principalmente de fatores genéticos.

\subsubsection{Patologias Mamárias}

Uma patologia é considerada como uma anormalidade que surge nos tecidos. O termo neoplasia descreve aquelas patologias que aparecem na forma de tumores ou massas estranhas ao organismo, referindo-se também a fibrose e angiogênese (aumento da vascularização) associados ao desenvolvimento do tumor (Conceição 2008). De acordo com a natureza patológica, as neoplasias ou tumores mamários podem ser classificados como benigno e maligno. A figura 2.2 apresenta um organograma representando os tipos de tecidos, normais e neoplásicos e dentre os neoplásicos aqueles que são considerados como uma lesão benigna ou maligna.

As neoplasias benignas possuem como característica um crescimento lento e seu tecido de sustentação, 
estroma, são semelhantes ao de tecidos normais, no que se refere a não ocorrência de invasão tecidual. As neoplasias malignas são originadas por células geneticamente modificadas, que sofreram mutações em seu DNA, e a multiplicação dessas células, além de exagerada e desordenada, em alguns casos é também invasiva, ou seja, invade os tecidos adjacentes, processo denominado de metástase. Em alguns casos o tecido cresce tão rapidamente que não há suporte sanguíneo necessário, provocando necroses (Cotran et al. 1989). Somente as neoplasias malignas podem ser denominadas como câncer.

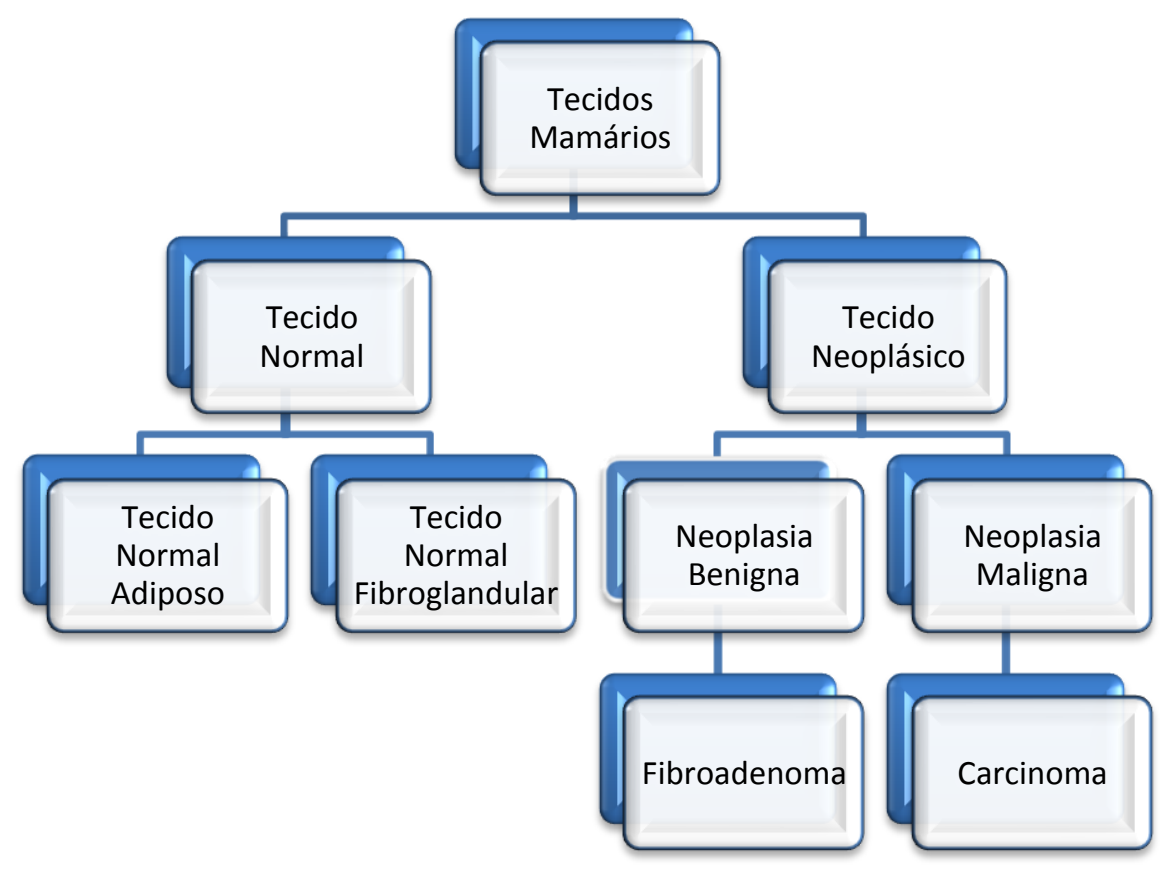

Figura 2.2: Classificação dos tecidos e os tipos de neoplasias.

\subsubsection{Neoplasias Benignas}

As neoplasias benignas, não apresentam grande risco à saúde de seus portadores se corretamente tratadas. Caracterizam-se por um crescimento lento em seu tecido de sustentação (estroma), sendo semelhante aos tecidos normais. Dentre as diversas neoplasias benignas mamárias, destaca-se o fibroadenoma. Este constitui a neoplasia mamária mais comum, atingindo principalmente mulheres com idade inferior a 30 anos. Trata-se de uma lesão do lóbulo mamário, sendo formada pela proliferação de tecido conjuntivo e 
epitélio. O tecido conjuntivo é composto por células fusiformes contendo por vezes elementos mesenquimais como gordura, músculo liso, cartilagem e osso. Em alguns casos, ao redor dos ductos o estroma é mais celular e mitoses são mais comuns, sugerindo interação epitélio-estroma (Schmitt, 2000). Apresentam características típicas, são bem limitados, indolores, móveis e de contornos arredondados.

\subsubsection{Neoplasias Malignas}

As neoplasias malignas são formadas por células geneticamente alteradas apresentando um volume maior e invadindo os tecidos adjacentes. Em alguns casos o tecido cresce tão rapidamente que não há suporte sanguíneo necessário, provocando necroses. Mecanismos de interação entre as células neoplásicas e o endotélio vascular, propiciam o aparecimento em órgãos distantes, na maioria das vezes, causadoras do óbito em pacientes.

A maioria dos casos de câncer de mama ocorre nos ductos ou nos lóbulos, sendo denominados respectivamente ductais e lobulares. Caso a doença prolifere além dos ductos ou lóbulos atingindo os tecidos vizinhos, é dita infiltrativa ou invasiva. A doença que está contida dentro dos ductos e lóbulos é denominada "in situ". Os carcinomas são a maioria das neoplasias malignas da mama, sendo o carcinoma ductal invasivo, o tipo mais comum.

\subsection{Fontes de raios $X$}

Wilhelm C. Roentgen descobriu um tipo desconhecido de radiação em 1895 que chamou de raios X. Os raios $\mathrm{X}$ descrevem uma grande região no espectro eletromagnético, com intervalo de energia de centenas de elétron-volts (raios X moles, próximo à radiação ultravioleta) até energias de centenas de keV (raios X duros, próximos aos raios $\gamma$ ), figura 2.3, e tem a propriedade de penetrar em materiais o que permite inspecionar o interior de objetos. Imediatamente após sua descoberta, as aplicações para este tipo de radiação se tornaram evidentes principalmente na medicina, através de radiografias. 


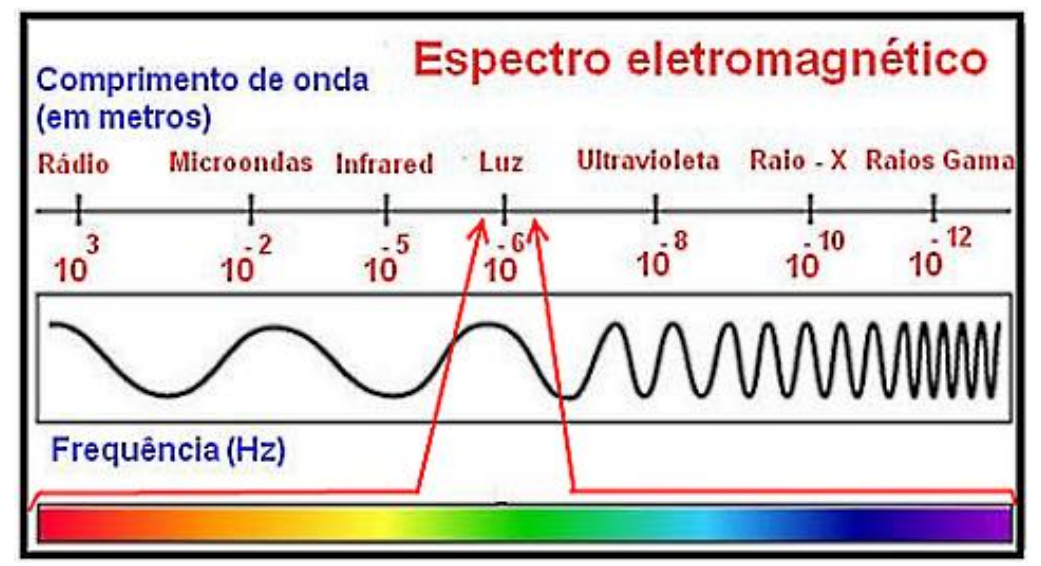

Figura 2.3: Espectro eletromagnético (http://bussoladeplasma.wordpress.com/tag/ondas/)

\subsubsection{Tubo de raios $X$}

Em um tubo de raios $\mathrm{X}$ existe um circuito elétrico constituído principalmente de um cátodo e um ânodo. O cátodo é um filamento que quando aquecido libera elétrons por efeito termoiônico, já o ânodo é o alvo onde estes elétrons colidem. Entre o cátodo e o ânodo existe um campo elétrico criado por um potencial da ordem de dezenas de $\mathrm{kV}$, que aceleram os elétrons do cátodo em direção ao ânodo. No ânodo, a energia acumulada pela interação dos elétrons com o alvo (ânodo) é convertida principalmente na produção de calor, sendo que apenas 1-2\% é convertida em produção de radiação (raios X). O espectro de energia de um tubo de raios $\mathrm{X}$ apresenta uma componente contínua (bremsstrahlung, raios $\mathrm{X}$ de frenagem ou radiação branca) e outra discreta (raios X característicos). A radiação branca é formada pela desaceleração dos elétrons no ânodo através de interações coulombianas inelásticas. Já os raios X característicos são fótons de energia discreta, resultantes do preenchimento de uma vacância deixada por um elétron de uma camada mais interna (que interagiu com elétrons provenientes do cátodo) por outro elétron de uma camada superior mais energética. As intensidades entre a radiação branca e a característica dependem do tipo de alvo e da tensão aplicada, e, além disso, podem ser modificadas através do uso de filtros (Attix, 1986). Na figura 2.4, observam-se exemplos de um tubo de raios X e de um espectro de energia com a especificação da radiação contínua e dos picos de raios X característicos. 

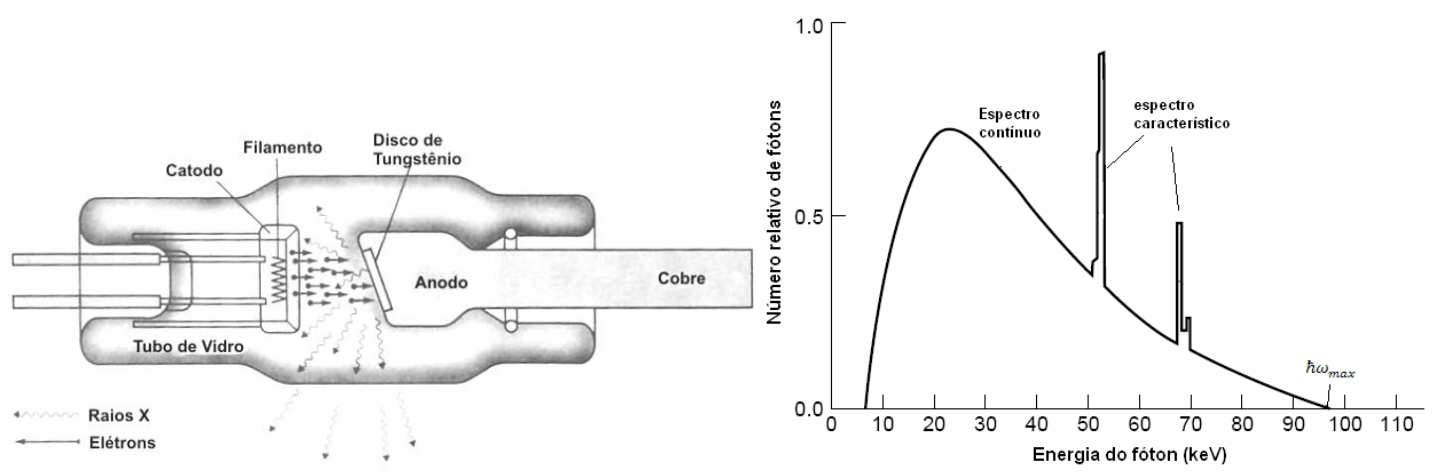

Figura 2.4: Exemplificação de um tubo de raios $X$ com anodo de tungstênio (W) e seu respectivo espectro (Attix, 1986).

\subsection{Interação da Radiação com a Matéria}

A descoberta dos raios $\mathrm{X}$ e sua capacidade de tornar possível a visualização de estruturas internas do corpo humano revolucionou a medicina da época principalmente com relação ao radiodiagnóstico. Assim, o estudo das interações da radiação com a matéria começou a ser intensificado visando melhorar a qualidade da imagem fornecida pelos raios X e, também, diminuir os riscos associados com a exposição à radiação. A seguir serão descritos os principais efeitos de interação de fótons com a matéria. As interações dos raios $\mathrm{X}$ com a matéria dependem basicamente da energia dos fótons incidentes e do material que constitui o alvo (número atômico e densidade). Os principais fenômenos de interação da radiação com a matéria considerando a faixa de energia utilizada em radiodiagnóstico $(\mathrm{E}<140 \mathrm{keV})$ são o efeito fotoelétrico e os espalhamentos inelástico e elástico. Em particular, para fótons com energia utilizada em mamografia $(17,44 \mathrm{keV})$ numa amostra de tecido mamário médio (50\% adiposo e $50 \%$ glandular), $69,76 \%$ do total de interações ocorrem por efeito fotoelétrico, $10,42 \%$ por espalhamento elástico e 19,82\% por espalhamento inelástico (Berger e Hubbell, 1987). 


\subsubsection{Efeito Fotoelétrico}

Como resumido por Tomal (2007), o efeito fotoelétrico é caracterizado pela transferência total da energia do fóton incidente a um único elétron orbital, que é ejetado com uma energia bem definida $T=h v-E_{b}$, onde $E_{b}$ é a energia de ligação do elétron no átomo. O processo fotoelétrico encontra-se classicamente esquematizado na figura 2.5. Para que o efeito fotoelétrico ocorra, a energia do fóton incidente deve ser maior ou igual à energia de ligação do elétron no átomo.

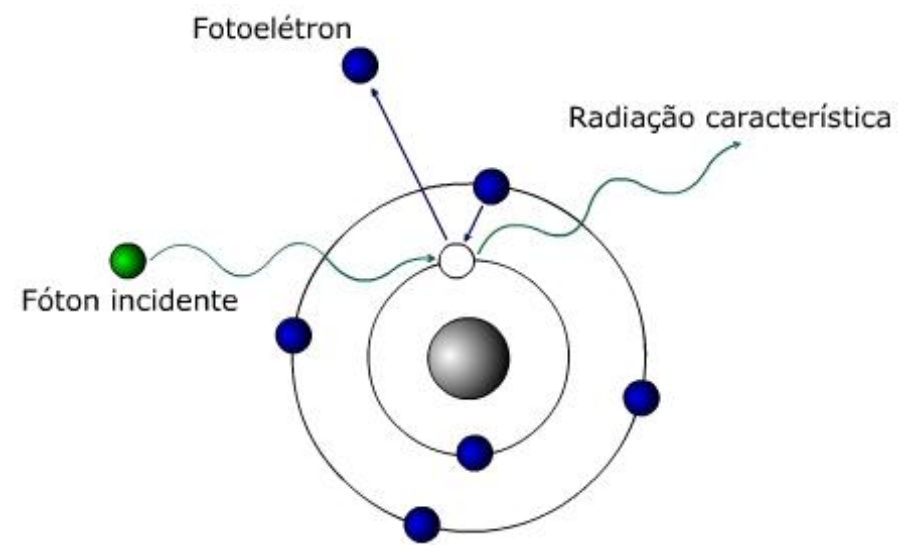

Figura 2.5: Representação esquemática do efeito fotoelétrico (http://efeitofotoeletricoecompton.webnode.com.br).

A probabilidade de que um fóton sofra um processo fotoelétrico é dado pela seção de choque de interação para este efeito, $\tau$, cuja obtenção teórica é mais difícil se comparada aos outros tipos de interação, devido à energia de ligação do elétron no átomo. Cálculos precisos necessitam de computações numéricas elaboradas usando aproximações da função de onda atômica (Anderson, 1984). A variação da seção de choque por átomo para o efeito fotoelétrico, na região de energias $h v \leq 100 \mathrm{keV}$, onde o efeito fotoelétrico é predominante, é proporcional a (Attix, 1986):

$$
\tau \propto \frac{Z^{4}}{(h v)^{3}}
$$


A partir da equação (2.1), verifica-se que a probabilidade do efeito fotoelétrico diminui rapidamente com o aumento da energia do fóton incidente, além de variar de forma significativa com o número atômico $Z$ do elemento. O efeito fotoelétrico é o tipo de interação mais importante de fótons de baixa energia com a matéria, sendo predominante para materiais de alto número atômico $\mathrm{Z}$, sendo o efeito responsável pela formação da imagem radiográfica (Attix, 1986).

\subsubsection{Espalhamento Inelástico}

Se o fóton incidente transfere parte de sua energia para os elétrons do meio, na forma de energia cinética, desviando-se de sua trajetória inicial, temos o chamado espalhamento inelástico ou incoerente. O espalhamento incoerente foi tratado inicialmente por Compton que considerou a radiação incidente como pacotes de onda quantizados com energia $h v$ (Johns e Cunninghan, 1983). Por isso, esse processo também recebe o nome de espalhamento Compton. O espalhamento incoerente está classicamente ilustrado na Figura 2.6.

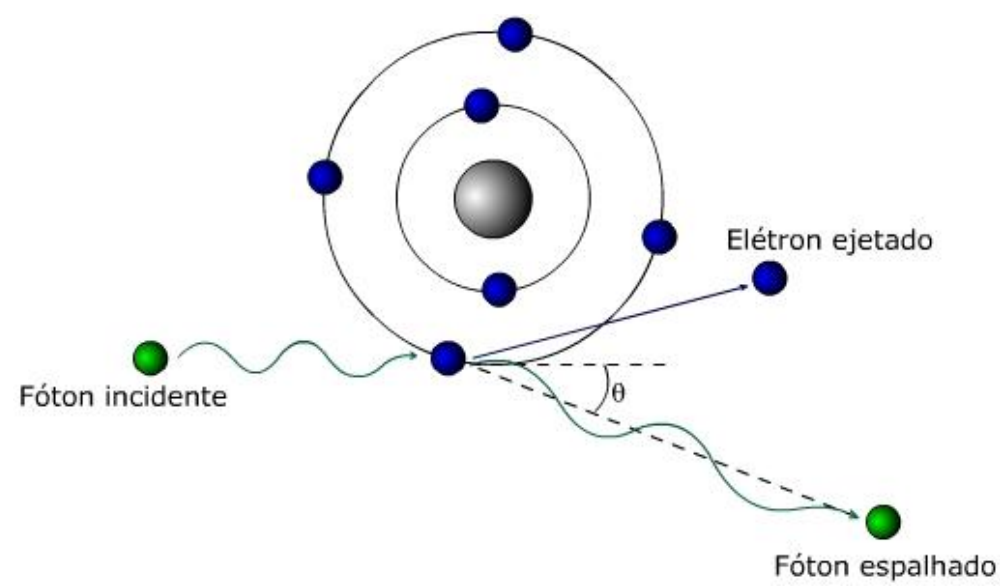

Figura 2.6: Representação esquemática do espalhamento incoerente (http://efeitofotoeletricoecompton.webnode.com.br).

As abordagens para explicar o espalhamento incoerente podem resumir-se em duas: por elétron livre (Klein-Nishina) e por elétron ligado (Compton Atômico). 


\subsubsection{Espalhamento Incoerente por Elétron Livre}

A expressão para a seção de choque diferencial de espalhamento, neste caso, foi obtida em 1928 por Klein e Nishina, que aplicou métodos de eletrodinâmica quântica considerando um feixe não-polarizado e um elétron em repouso (Johns e Cunninghan, 1983), sendo dada por:

$$
\left(\frac{d \sigma}{d \Omega}\right)_{K N}=\left(\frac{d \sigma}{d \Omega}\right)_{T h} F_{K N}=\frac{r_{0}^{2}}{2}\left(1+\cos ^{2} \theta\right) F_{K N}
$$

onde o fator $F_{K N}$ é o fator de Klein-Nishina, que é escrito como:

$$
F_{K N}=\left\{\frac{1}{1+\alpha \cdot(1-\cos \theta)}\right\}^{2} \times\left\{1+\frac{\alpha^{2} \cdot(1-\cos \theta)^{2}}{[1+\alpha \cdot(1-\cos \theta)] \times\left(1+\cos ^{2} \theta\right)}\right\}
$$

onde $\alpha=h v / m_{0} c^{2}$.

A probabilidade total para a interação de um fóton com um elétron livre através do espalhamento Compton é obtida integrando-se a seção de choque diferencial, dada pela equação (2.2), em todo intervalo de ângulo sólido (Johns e Cunninghan, 1983). Este procedimento fornece a seção de choque de KleinNishina por elétron, escrita como:

$$
\sigma=\frac{3}{4} \sigma_{T}\left\{\left(\frac{1+\alpha}{\alpha^{2}}\right) \times\left(\frac{2(1+\alpha)}{1+2 . \alpha}-\frac{\ln (1+2 . \alpha)}{\alpha}\right)+\frac{\ln (1+2 . \alpha)}{2 . \alpha}-\frac{1+3 . \alpha}{(1+2 . \alpha)^{2}}\right\}
$$


onde $\sigma_{T}=66,525.10^{-30} \mathrm{~m}^{2}$ é seção de choque de espalhamento Thomson para um elétron livre

\subsubsection{Espalhamento Incoerente por Elétron Ligado}

Uma aproximação mais realista consiste em considerar a interação de um fóton com um elétron ligado a um material. Definindo uma função do espalhamento incoerente $S(x, Z)$, a seção de choque diferencial, neste caso, pode ser escrita como:

$$
\left(\frac{d \sigma}{d \Omega}\right)_{i n c}=S(x, Z)\left(\frac{d \sigma}{d \Omega}\right)_{K N}
$$

onde $\left(\frac{d \sigma}{d \Omega}\right)_{K N}$ é a seção de choque diferencial obtida para o elétron livre. Valores para $S(x, Z)$ encontram-se tabulados por Hubbell et al. 1975 para uma grande quantidade de elementos químicos. E $x=\lambda^{-1} \operatorname{sen}(\theta / 2)$, é proporcional ao momento transferido $q$ na interação do fóton com o átomo e $\mathrm{Z}$ é o número atômico.

Uma vez que no espalhamento incoerente os comprimentos de onda dos fótons espalhados são diferentes entre si, não existe uma relação de interferência entre as várias moléculas ou átomos que compõe o conjunto. Pode-se supor que cada átomo contribui de forma independente para o espalhamento (Modelo Atômico Independente, MAI) (Johns e Yaffe, 1983).

\subsubsection{Espalhamento Elástico}

Quando um fóton interage com a matéria desviando-se da sua trajetória inicial de modo que ele não sofra variação na sua energia, temos o chamado espalhamento elástico ou coerente. Este fenômeno pode ser explicado usando conceitos do eletromagnetismo clássico como segue: o campo elétrico da onda eletromagnética, com comprimento de onda $\lambda$, associado a esse fóton dá origem a uma vibração dos 
elétrons presentes na matéria. Devido a essa aceleração os elétrons emitem radiação de mesmo comprimento de onda $\lambda$ que a incidente (Johns e Cunninghan, 1983). As abordagens para explicar o espalhamento coerente podem resumir-se em duas: por elétron livre e por elétron ligado.

\subsubsection{Espalhamento Coerente por Elétron Livre}

Se o espalhamento elástico ocorre devido somente a um elétron livre, ele também recebe o nome de espalhamento Thomson. Considerando radiação eletromagnética não polarizada e apenas suposições de eletromagnetismo clássico, Thomson obteve a seguinte expressão para a seção de choque diferencial por elétron (Johns e Cunninghan, 1983):

$$
\left(\frac{d \sigma}{d \Omega}\right)_{T h}=\frac{r_{0}^{2}}{2}\left(1+\cos ^{2} \theta\right)
$$

onde $r_{0}=\frac{1}{4 \pi \varepsilon_{0}} \frac{e^{2}}{m_{0} c^{2}}=2,82 \times 10^{-15} \mathrm{~m}$ é o raio clássico do elétron e $\theta$ é o ângulo de espalhamento. A seção de choque total $\sigma_{T}=66,525 \times 10^{-30} \mathrm{~m}^{2}$ é chamada de coeficiente de espalhamento clássico Thomson para um elétron livre.

\subsubsection{Espalhamento Coerente por Elétron Ligado a um Material}

Uma aproximação mais realista considera a interação de um fóton com o elétron ligado a um material (átomo ou molécula). O tratamento para este efeito propõe que a seção de choque diferencial seja uma modificação da seção de choque diferencial de Thomson através do fator de forma $F(x, Z)$ : 


$$
\left(\frac{d \sigma}{d \Omega}\right)_{\text {Ray }}=(F(x, Z))^{2} \cdot\left(\frac{d \sigma}{d \Omega}\right)_{T h}
$$

O fator de forma $F(x, Z)$ é a transformada de Fourier da distribuição de cargas do material.

Uma vez que o fator de forma $F(x, Z)$ leva em conta as interferências dos elétrons dentro do material, este pode ser considerado de várias maneiras (Johns e Yaffe, 1983):

(i) Levando em conta os efeitos de interferência entre as moléculas. Neste caso para determinar o fator de forma é necessário conhecer a distribuição de densidade eletrônica, dada pela convolução da distribuição dos elétrons dentro das moléculas individuais, com a distribuição de posição e orientação das moléculas umas em relação às outras.

(ii) Levando em conta a interferência dos elétrons dentro de uma mesma molécula. Nesse caso o fator de forma é calculado considerando a distribuição de probabilidade dos elétrons dentro da molécula.

(iii) Uma terceira aproximação, mais simples, considera apenas a interferência de elétrons dentro de um mesmo átomo. Essa aproximação também é chamada de Modelo Atômico Independente (MAI).

Neste trabalho, por motivos de simplificações, utilizaremos a seção de choque calculada a partir do modelo atômico independente, visto que estes valores encontram-se tabulados na literatura para uma grande quantidade de elementos químicos (Hubbell et al, 1975) e podem ser calculados para qualquer material a partir de sua composição química, usando a regra das misturas (Chan et al. 1983).

Considerando um material puro com número atômico $Z$, a seção de choque para o espalhamento coerente, é proporcional a:

$$
\sigma_{R} \tilde{\propto} \frac{Z^{2}}{(h v)^{2}}
$$


O espalhamento coerente ocorre principalmente para baixas energias, e não contribui para as grandezas dosimétricas, diretamente, pois nenhuma energia é transferida para qualquer partícula carregada, nem qualquer ionização ou excitação é produzida (Attix, 1986).

\subsubsection{O espalhamento no Radiodiagnóstico}

As imagens radiográficas convencionais são obtidas através das diferenças de coeficientes de atenuação entre os diversos tipos de tecidos, detectando corpos de diferentes densidades e formas em um dado material. A radiação transmitida, composta da radiação primária e espalhada, impressiona um receptor de imagem, geralmente uma combinação tela-filme, gerando um padrão de contraste no filme (Johns e Cunningham, 1983; Sprawls, 1995). Onde a radiação primária é a responsável pela formação da imagem e a radiação espalhada, em contrapartida, causa distorções na imagem radiográfica.

O conceito de considerar o espalhamento como uma desvantagem vem mudando ultimamente (Speller e Horrocks, 1991). Estudos recentes mostram que experiências de espalhamento de raios X fornecem informações estruturais sobre a composição dos tecidos, fornecendo meios alternativos para distinguir patologias (Kidane et al. 1999; Poletti et al. 2001, 2002a, 2002b). Dessa forma, faz-se necessário à obtenção de medidas precisas dos perfis de espalhamento dos diferentes tecidos humanos (Poletti et al. 2004).

\subsection{Coeficiente de Atenuação Linear}

A probabilidade total de uma interação é representada pela seção de choque atômica total, sendo escrita como a soma das seções de choque dos processos individuais de interação de fótons com a matéria. Na faixa de energia de interesse em radiodiagnóstico, a seção de choque total pode ser escrita como:

$$
{ }^{a} \sigma_{\text {TOT }}=\tau+\sigma_{R}+\sigma_{\text {incoe }}
$$


onde $\tau$ é a seção de choque fotoelétrica, $\sigma_{R}$ e $\sigma_{\text {incoe }}$ são as secções de choque para o espalhamento coerente e incoerente, respectivamente.

O coeficiente de atenuação de um material está relacionado com a seção de choque total e o número de átomos por unidade de volume $\left(n_{v}\right)$, através da seguinte forma (Hubbell, 1982; Hubbell, 1999):

$$
\mu=n_{v} \cdot{ }^{a} \sigma_{T O T}
$$

O coeficiente de atenuação linear depende do estado físico ou fase do material, pois é uma função do número de átomos presentes em uma camada do material. Uma grandeza mais fundamental é o coeficiente de atenuação mássico $(\mu / \rho)$, que independe do estado físico (Johns e Cunninghan, 1983).

A dependência do coeficiente de atenuação mássico com a seção de choque por átomo e com a seção de choque por elétron $\left({ }^{e} \sigma_{T O T}\right)$, é da forma:

$$
\frac{\mu}{\rho}={ }^{a} \sigma_{\text {TOT }}\left(\frac{N_{A}}{A}\right)={ }^{e} \sigma_{\text {TOT }}\left(N_{A} \cdot \frac{Z}{A}\right)
$$

onde $N_{A}$ é o número de Avogrado, $A$ é o peso atômico do elemento de interesse e $N_{A} Z / A$ é o número de elétrons por grama do material.

\subsection{Regra das Misturas}

A regra das misturas permite obter o coeficiente de atenuação mássico de uma mistura de composição química conhecida a partir dos coeficientes tabulados para cada elemento que compõe o material. 
Para um componente homogêneo, o coeficiente de atenuação mássico pode ser calculado aproximadamente a partir da soma dos pesos dos elementos constituintes (Bragg, 1914 apud Attix, 1986):

$$
\left(\frac{\mu}{\rho}\right)_{m i s}=\sum_{i} w_{i}\left(\frac{\mu}{\rho}\right)_{i}
$$

onde $w_{i}$ é a fração do peso de i-ésimo elemento constituinte, e $(\mu / \rho)_{i}$ é o coeficiente de atenuação mássico deste elemento. A regra das misturas ignora qualquer efeito de mudança na função de onda do átomo como resultado do arranjo molecular, químico e cristalino, sendo portanto uma aproximação (Jackson e Hawkes, 1981).

A regra das misturas fornece um meio de obter valores dos coeficientes de interação para uma infinidade de compostos químicos, que servem como uma boa aproximação para descrever a interação da radiação com estes compostos, bem como para verificar e validar resultados experimentais. 


\section{CAPÍTULO 3}

\section{MATERIAIS E METODOS}

\subsection{Amostras de tecidos biológicos e materiais tecido-equivalente}

As amostras de tecido mamário humano normal (adiposo e fibroglandular) e neoplásicas (fibroadenoma e carcinoma) analisadas neste trabalho foram fornecidas pelo Departamento de Patologia do Hospital das Clínicas da Faculdade de Medicina de Ribeirão Preto (DP-HCFMRP). Este material era resíduo de tecidos retirados em procedimentos cirúrgicos de mastectomia (cirurgia para retirada de parte da mama invadida por tumores) e mastoplastia (cirurgia plástica para redução da mama). As amostras de tecido colhidas eram determinadas de forma a ser o mais homogêneo possível e em quantidade suficiente para ser irradiada. Essas amostras foram armazenadas a temperatura ambiente e em formol tamponado (10\%) para manter a integridade física do tecido. A classificação histológica das amostras coletadas foi realizada através de uma análise microscópica por médicos patologistas do departamento de patologia do HCFMRP. Ao todo, neste trabalho, foram analisadas 100 amostras de tecidos mamários, sendo: 35 amostras de tecido normal adiposo, 24 amostras de tecido normal fibroglandular, 11 amostras de fibroadenoma (tecido neoplásico benigno) e 30 amostras de carcinoma (tecido neoplásico maligno), como apresentado na figura 3.1. A utilização das amostras de tecido mamário humano foi aprovada pelo Comitê de Ética do Hospital das Clínicas (HCFMRP) e pelo Comitê de Ética da Faculdade de Filosofia Ciências e Letras de Ribeirão Preto (FFCLRP).

Além disso, neste trabalho, utilizou-se materiais tecido-equivalentes com os objetivos de: (i) construir curvas de calibração (padrões) e validar os procedimentos experimentais utilizados neste trabalho (nylon, poliacetato, e água líquida). Sendo que estes materiais foram escolhidos por possuírem coeficientes de atenuação linear similares aos dos tecidos mamários humano estudados (White et al. 1980) e ainda por já terem tido suas propriedades de espalhamento estudadas em outros trabalhos presentes na literatura 
(Kosanetzky et al. 1987; Poletti et al. 2002b) e (ii) verificar quais desses materiais podem simular adequadamente os tecidos humano adiposo, muscular e ósseo (nylon, poliacetato, polimetilmetacrilato (PMMA), água, músculo-equivalente (062A-10: Computerized Imaging Reference System Inc.- CIRS, Norfolk, VA, USA), osso-equivalente (062A-26: CIRS, Norfolk, VA, USA) e adiposo-equivalente (062A-11: CIRS, Norfolk, VA, USA)). A tabela 3.1 mostra a composição e a densidade física para alguns destes materiais tecido-equivalente utilizados.

\section{Classificação das Amostras}

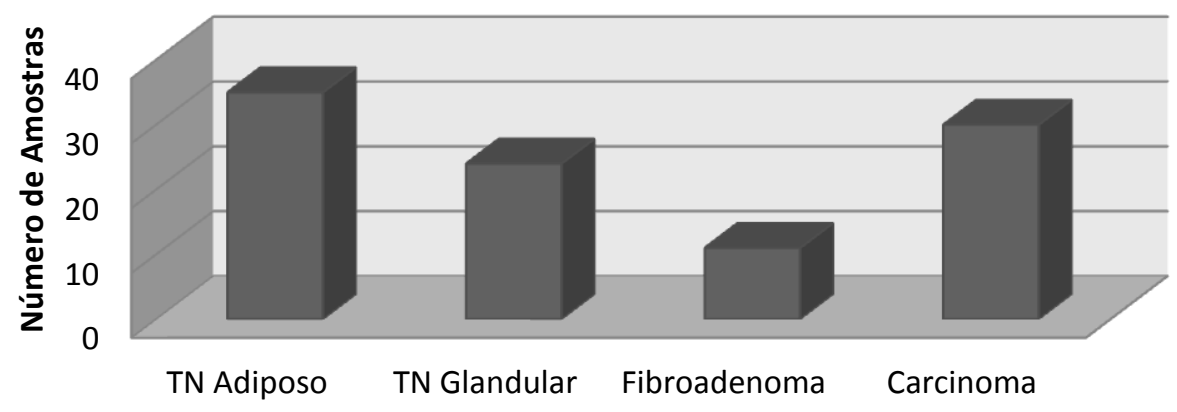

Figura 3.1: Classificação histológica das amostras utilizadas neste trabalho, bem como a quantidade de amostras em cada classe de classificação.

Tabela 3.1

Materiais tecido-equivalentes - Densidades e Composição

\begin{tabular}{ccc}
\hline Material tecido-equivalente & $\begin{array}{c}\text { Densidade } \\
\left(\mathrm{g} / \mathrm{cm}^{3}\right)\end{array}$ & Composição \\
\hline Nylon & 1.14 & $\left(\mathrm{C}_{12} \mathrm{H}_{22} \mathrm{O}_{8} \mathrm{~N}_{2}\right)_{\mathrm{n}}$ \\
Poliacetato & 1.41 & $\left(\mathrm{C}_{4} \mathrm{H}_{6} \mathrm{O}_{2}\right)_{\mathrm{n}}$ \\
PMMA & 1.17 & $\left(\mathrm{C}_{5} \mathrm{H}_{8} \mathrm{O}_{2}\right)_{\mathrm{n}}$ \\
Água líquida & 1.00 & $\mathrm{H}_{2} \mathrm{O}$ \\
\hline
\end{tabular}




\subsection{Forma e Espessura das amostras}

Os tecidos mamários foram cortados com dimensões adequadas para serem acoplados em um recipiente cilíndrico de acrílico (porta-amostra) de diâmetro interno $18 \mathrm{~mm}$ e profundidade de $4 \mathrm{~mm}$ (figura 3.2). Uma fina camada de policloreto de vinila (filme PVC) com espessura de 1,5 $\pm 0,2 \mu \mathrm{m}$ foi utilizada para recobrir o tecido nas extremidades do porta-amostra, de forma que a amostra de tecido apresentasse uma superfície o mais regular e homogênea possível. A espessura das amostras foi escolhida com o intuito de prover suficiente espalhamento simples e ao mesmo tempo minimizar a probabilidade de espalhamento múltiplo presentes nos perfis de espalhamento medidos (Poletti et al. 2002c) e também minimizar as incertezas nas medições relativas aos cálculos dos coeficientes de atenuação linear (Tomal et al. 2010).

O coeficiente de atenuação linear é definido, para cada energia E do fóton, pela equação (3.1). Dessa forma, através de medidas da intensidade incidente $I_{0}(E)$ e transmitida $I_{t}(E)$ através da amostra de tecido de espessura t, pode-se obter $\mu(E)$ (Conner et al. 1970, Tomal et al. 2010).

$\mu(E)=-\frac{1}{t}\left(\frac{I_{t}(E)}{I_{0}(E)}\right)$

A variância no valor do coeficiente de atenuação linear da cada amostra, $\sigma_{\mu}^{2}$, é obtida através de:

$\sigma_{\mu}^{2}=\sigma_{t}^{2}\left[\frac{1}{t^{2}} \ln \left(\frac{I_{0}}{I_{t}}\right)\right]^{2}+\sigma_{I_{0}}^{2}\left[\frac{1}{I_{0} \cdot t}\right]^{2}+\sigma_{I_{t}}^{2}\left[\frac{1}{I_{t} \cdot t}\right]^{2}$

Onde $\sigma_{t}^{2}$ representa a variância na espessura t, $\sigma_{I_{0}}^{2}$ e $\sigma_{I_{t}}^{2}$ são as variâncias nas intensidades $I_{0}$ e $I_{t}$ respectivamente.

Considerando que a intensidade da radiação siga uma distribuição de Poisson (Johns e Cunningam 1983), temos $\sigma_{I_{0}}^{2}=I_{0}$ e $\sigma_{I_{t}}^{2}=I_{t}$. Supondo também que as incertezas na medida da espessura $\mathrm{t}$ (as espessuras foram determinadas utilizando um relógio comparador centesimal com precisão de $0,003 \mathrm{~mm}$ ) são pequenas se comparadas às incertezas estatísticas na contagem do número de fótons, assim a variância na medida do coeficiente de atenuação linear torna-se: 
$\sigma_{\mu}^{2}=\frac{1}{I_{0} t^{2}}\left[1+e^{\mu t}\right]$

Diferenciando a equação (3.3) e igualando a zero, encontra-se a espessura ótima que minimiza a variância nas medidas experimentais, sendo aproximadamente:

$t_{\text {ótimo }} \cong\left(2.2 \cdot \mu^{-1}\right) \mathrm{cm}$

Foram utilizadas amostras com espessura de aproximadamente $4 \mathrm{~mm}$ para todo o intervalo de energia analisado. Este valor foi estimado utilizando os valores do coeficiente de atenuação de tecido mamário tabulados por Hubbell (Hubbell, 1982).

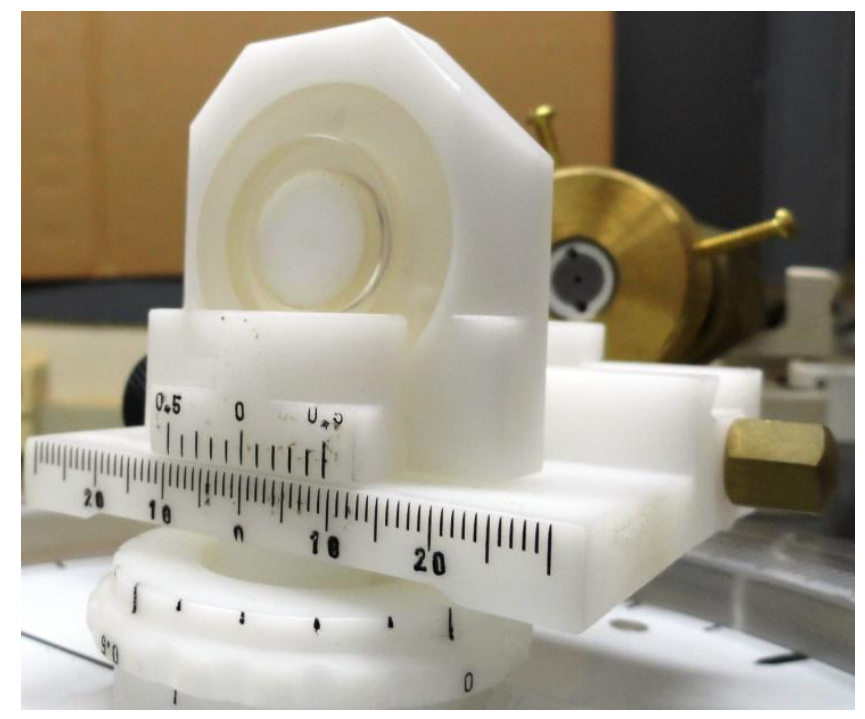

Figura 3.2: Porta-amostra utilizado na medida do perfil de espalhamento e coeficiente de atenuação linear das amostras de tecido e material tecido-equivalente.

\subsection{Arranjo Experimental}

O arranjo experimental foi construído para medir a distribuição de energia dos fótons espalhados e transmitidos simultaneamente. Este arranjo foi montado no Laboratório de Física das Radiações e Dosimetria, do Departamento de Física da Faculdade de Filosofia Ciências e Letras de Ribeirão Preto 
(DF-FFCLRP, USP). O esquema do arranjo experimental do Sistema de raios X Dispersivo em Energia (SRXDE) desenvolvido neste trabalho está exposto na figura 3.3. O arranjo experimental consistiu-se de um tubo de raios X (Philips PW 2215/20) com anodo de tungstênio (W) operando a 60kVp com uma filtração intrínseca de $1 \mathrm{~mm}$ de $\mathrm{Ni}$ com o intuito de atenuar os picos de raios X característico provenientes do alvo de tungstênio, um goniômetro, e dois sistemas de detecção: um detector de telureto de cádmio (CdTe) da Amptek (modelo XR - 100T), posicionado a um ângulo de 7 graus com relação ao feixe incidente, usado para medir a distribuição de energia dos fótons espalhados, e um detector de silício (Silicon Drift Detector - SDD) da Amptek (modelo X-123), posicionado a zero graus com relação ao feixe incidente, usado para medir a distribuição de energia dos fótons transmitidos pela amostra ou dos fótons incidentes sobre a amostra (medidos sem a presença da amostra).

Um colimador cilíndrico $(\Phi=1 \mathrm{~mm})$ posicionado na saída do tubo de raios X foi utilizado para reduzir o tamanho do feixe. Além disso, um conjunto adicional de colimação de chumbo, com diâmetros de $2 \mathrm{~mm}$ e 0.4mm foram acoplados aos detectores CdTe e SDD, respectivamente. No caso do SDD a colimação é necessária para que o detector não sature devido à elevada quantidade de fótons atingindo seu volume sensível, bem como para diminuir os fótons espalhados detectados pelo detector (o ângulo sólido neste caso foi de $0.00453^{\circ}$ ) (Midgley, 2006). Em contrapartida, no caso do CdTe não há uma restrição específica para a colimação. Uma vez que, a quantidade de fótons espalhados que chegam ao detector não é suficiente para causar saturação, dessa forma, a colimação foi realizada de modo que o detector fosse capaz de "enxergar" todo o volume irradiado na amostra.
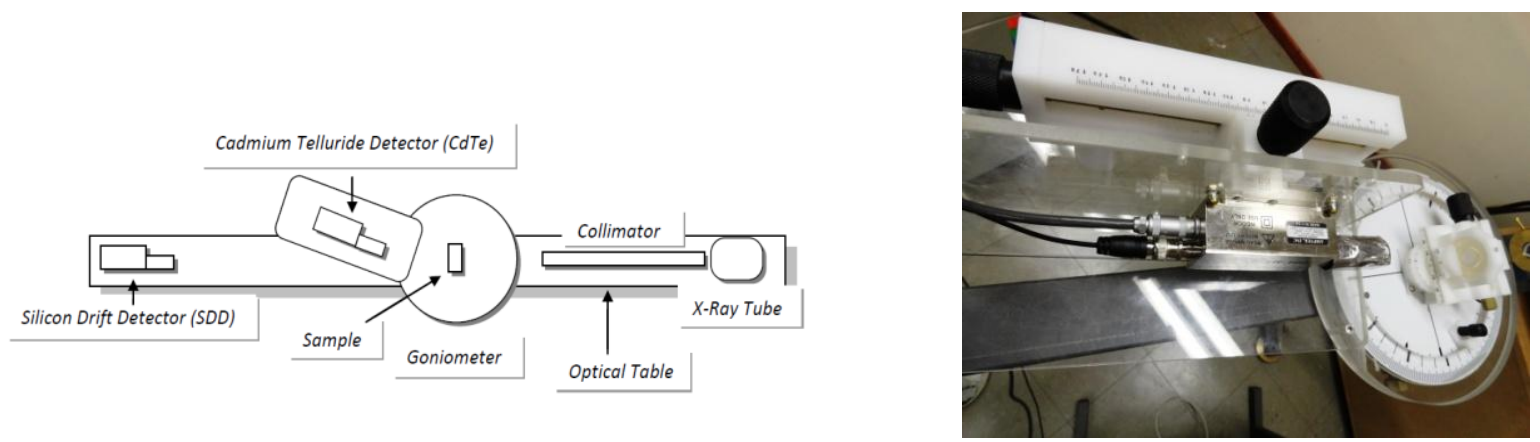

Figura 3.3: Arranjo experimental para medição das propriedades de atenuação e espalhamento. 
As amostras sob investigação foram posicionadas em um porta-amostra de acrílico (PMMA) com 8mm de diâmetro e, dessa forma, posicionada no centro do goniômetro, perpendicularmente ao feixe incidente (figura 3.2) . O tempo empregado na aquisição dos dados foi de aproximadamente 1000s para obtenção de uma adequada contagem estatística, com uma incerteza na contagem de fótons menor que 3\% nos dois espectros, transmitido e espalhado.

\subsubsection{Sistema de detecção}

\section{Características, Calibração e Função Resposta dos detectores}

O detector CdTe é composto por um diodo de CdTe com dimensões de 3mm x 3mm de área e 1mm de espessura, e densidade igual a $5,85 \mathrm{~g} / \mathrm{cm}^{3}$. Os eletrodos são compostos de Platina (Pt, $\left.0,2 \mu \mathrm{m}\right)$ no cátodo, e de Índio $(\mathrm{In}, 1,0 \mu \mathrm{m})$ no ânodo. O detector é montado sobre um substrato refrigerador termoelétrico (células Peltier), que é mantido a uma temperatura de aproximadamente $-30^{\circ}$. O sistema de detecção é isolado hermeticamente, e possui uma janela de Be com espessura de $100 \mu \mathrm{m}$. O sistema detector/préamplificador é conectado a um processador digital de pulsos (modelo PX4), que fornece uma tensão de polarização de 400V, e a um analisador multicanal (modelo MCA 8000A), com 2048 canais.

O sistema de detecção X-123 SDD é compacto e completo, combinando em um único dispositivo o detector SDD e o pré-amplificador (XR-100SDD), o processador digital de pulsos (DP5) e o multicanal, a fonte de alta tensão (PC5) e a interface com o computador. O cristal de silício possui espessura de $450 \mu \mathrm{m}$ e uma área de $7 \mathrm{~mm}^{2}$. Um sistema de colimadores internos (Internal Multilayer Collimator), composto de finas camadas de tungstênio, cromo, titânio e alumínio, com orifícios de área 4,5 $\mathrm{mm}^{2}$, é incluído em frente ao detector para reduzir a intensidade de background detectada. O detector é montado sobre um substrato refrigerador termoelétrico (células Peltier), que é mantido a uma temperatura de aproximadamente $-55^{\circ}$. O sistema de detecção é isolado hermeticamente, e possui uma janela de Be com espessura de $12,5 \mu \mathrm{m}$. Um potencial de polarização de $-261 \mathrm{~V}$ é aplicado ao detector.

A calibração dos detectores foi realizada através de medidas experimentais de espectros de fontes radioativas que apresentam picos de emissão na faixa de energia de interesse. O SDD foi calibrado 
utilizando fontes de $\mathrm{Fe}^{55}$ e $\mathrm{Am}^{241}$ (Picos em 5,89keV e 59,54keV, respectivamente). Já o detector CdTe foi calibrado através de uma fonte de $\mathrm{Am}^{241}$ e fluorescência do cobre $(\mathrm{Cu})$, o qual emite dois picos, $\mathrm{K}_{\alpha 1}=8.047 \mathrm{keV}(100 \%)$ e $\mathrm{K}_{\alpha 2}=8.027 \mathrm{keV}(51 \%)$. Entretanto, para a calibração utilizou-se o valor de energia de $8,04 \mathrm{keV}$ (valor médio), uma vez que, o sistema de detecção utilizado neste trabalho não possui capacidade para resolver os dois picos. As curvas de calibração do sistema de detecção foram determinadas a partir da correlação entre energia de emissão das fontes radioativas e o número do canal correspondente a cada energia. As curvas de calibração para os detectores CdTe e SDD são lineares e estão mostradas na figura 3.4 .
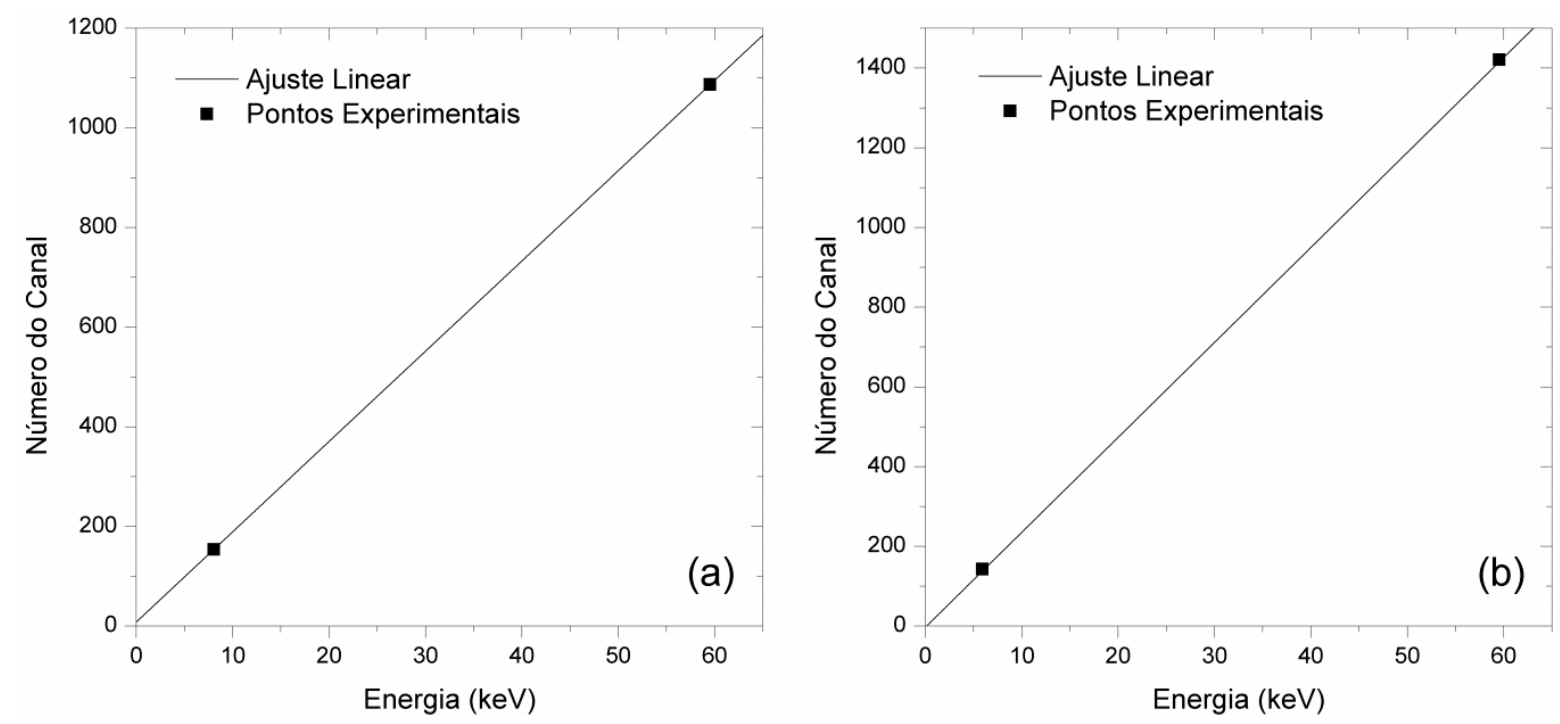

Figura 3.4: Curva de Calibração dos detectores. (a) CdTe e (b) SDD.

Uma correção muito importante que precisa ser feita é a que diz respeito à eficiência dos detectores usados neste trabalho. É necessário corrigir o espectro medido pela eficiência dos detectores, $\varepsilon(E)$, uma vez que, suas eficiências variam em função da energia do fóton incidente, como mostra a figura 3.5 (Tomal et al. 2012).

A eficiência do detector CdTe é alta para toda a faixa de energia utilizada em mamografia (acima de 90\% até $65 \mathrm{keV}$ ) devido ao elevado número atômico e alto Stopping Power do CdTe. Entretanto, sua curva de 
eficiência apresenta algumas descontinuidades (bordas de absorção) especificamente em 26,7keV e $31,8 \mathrm{keV}$, as quais correspondem às energias de ligação da camada $\mathrm{K}$ para o $\mathrm{Cd}$ e $\mathrm{Te}$, respectivamente (Miyajima, 2003). Por sua vez, as bordas de absorção em $11,5 \mathrm{keV}$ e $13 \mathrm{keV}$ são devido à atenuação dos fótons incidentes pelo contato de Platina, e isso corresponde à energia de ligação da camada L para este material (Miyajima, 2003). Agora, em contrapartida, a eficiência do detector SDD é máxima apenas para baixas energias (até $10 \mathrm{keV}$ ), sendo menor que $40 \%$ para energias acima de $20 \mathrm{keV}$. A baixa eficiência do SDD é deve-se a pequena espessura do seu cristal $(450 \mu \mathrm{m})$. Ambas são importantes por distorcer o espectro medido.

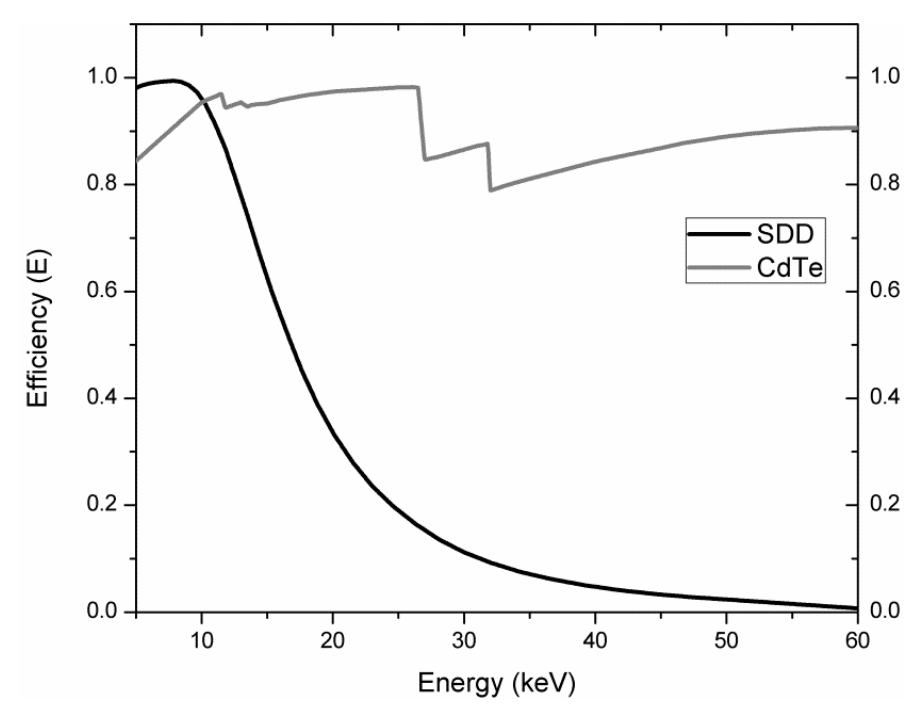

Figura 3.5: Relação da eficiência em função da energia para o detector Silicon Drift Detector (SDD) e para o detector de Telureto de Cádmio (CdTe) (Tomal et al. 2012).

\subsubsection{Otimização do Arranjo Experimental}

\subsubsection{Aspectos Gerais}

O sistema experimental foi construído e otimizado visando-se medir simultaneamente o feixe espalhado e o feixe transmitido através da amostra. E com este objetivo alguns parâmetros foram testados até se alcançar um estado ótimo do arranjo experimental proposto neste trabalho. Os parâmetros de vital importância são: distâncias entre os detectores e amostra, sistema de colimação acoplado aos detectores e ângulo de posicionamento do detector utilizado para medir o feixe espalhado. 


\subsubsection{Medidas de Transmissão}

Inicialmente, para o detector SDD, responsável pela medição do feixe incidente (sem amostra) e transmitido (com amostra) foi necessário determinar qual distância com relação à fonte de raios X e os diâmetros dos colimadores que devem ser escolhidos para se obter uma boa contagem estatística, entretanto, evitando sua saturação e a detecção de fótons espalhados. Para isso testou-se experimentalmente várias situações (com distâncias e colimadores diferentes) até se chegar a uma conjuntura de máxima intensidade de fótons detectados, porém mantendo um tempo morto sempre próximo de zero (neste trabalho, o tempo morto durante as medidas sempre esteve abaixo de $1 \%$ ).

\subsubsection{Medidas de Espalhamento}

No caso do detector de CdTe, a colimação não se trata de um parâmetro primordial, uma vez que, o detector não recebe uma quantidade de fótons espalhados suficiente para causar sua saturação. Sendo assim, o colimador foi construído de forma que o detector consiga "enxergar" toda a região irradiada na amostra e de modo que não obstrua o feixe transmitido pela amostra. Dessa forma, para este detector, os parâmetros mais importantes são: a distância com relação à amostra e o ângulo de espalhamento (ângulo de posicionamento com relação ao feixe incidente). Sendo assim, estudos detalhados desses parâmetros foram realizados para determinar qual a melhor situação de medição.

\subsubsection{3a Escolha do ângulo de espalhamento}

A figura 3.6 apresenta de forma teórica a seção de choque diferencial em função da energia $(\mathrm{keV})$ para o PMMA, em vários ângulos de posicionamento do detector responsável pela detecção do feixe espalhado. Nota-se que conforme aumenta o ângulo de coleta dos fótons espalhados, a curva da seção de choque fica cada contida em uma faixa cada vez mais estreita do espectro de energia. Ocupando uma faixa de aproximadamente $25 \mathrm{keV}$ para um ângulo de 20 graus e, em contrapartida, uma faixa superior a $80 \mathrm{keV}$ para um ângulo de 6 graus. Neste trabalho, utilizou-se um aparato experimental com capacidade de medição ótima na faixa de energia compreendida entre 10 e $60 \mathrm{keV}$ (este último valor definido pelo 
máximo valor de tensão do gerador utilizado). Dessa forma, para ângulos abaixo de 7 graus temos a presença de picos em regiões fora das energias de excitação utilizadas (picos localizados acima de $60 \mathrm{keV}$ ), além de causar a obstrução do feixe transmitido pela amostra, impedindo que este atinja o detector SDD. Da mesma forma, para ângulos mais elevados esses picos ficam localizados abaixo de $10 \mathrm{keV}$. Sendo assim, foi escolhido o ângulo de 7 graus.

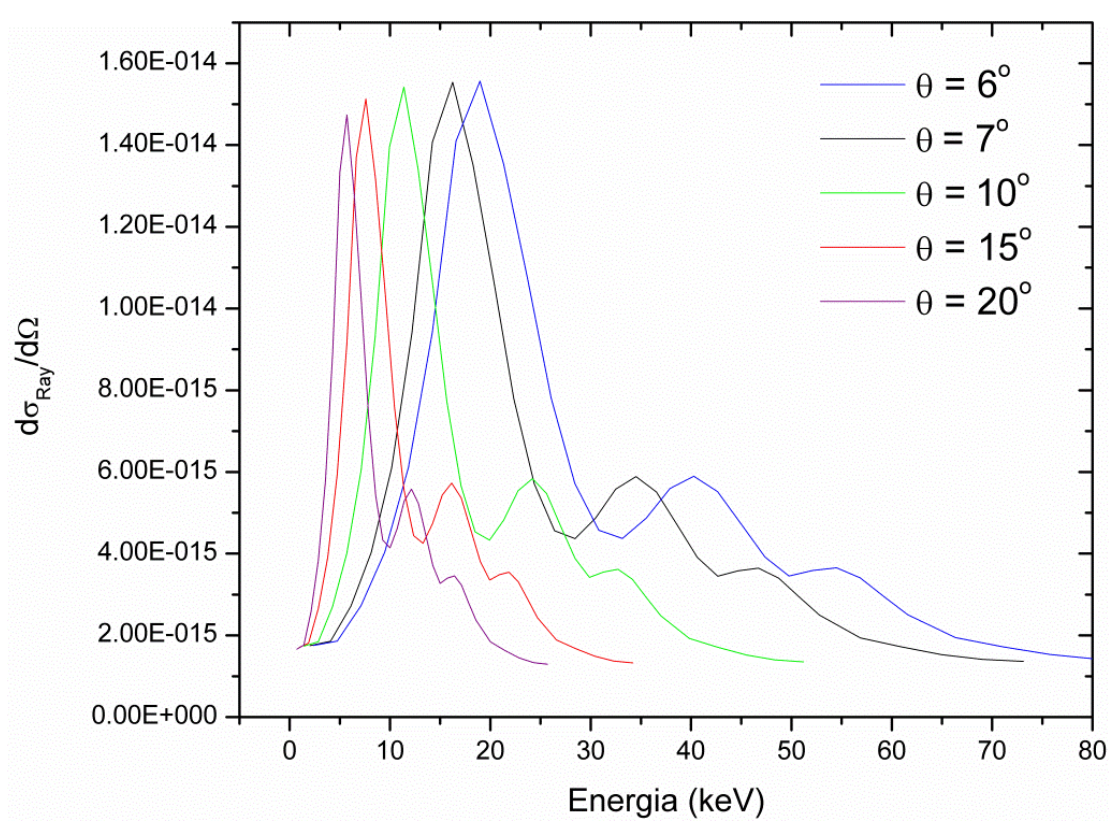

Figura 3.6: Comparação entre as seções de choque teóricas para diferentes ângulos de coleta do feixe espalhado.

\subsubsection{3b Distância entre fonte e detector (CdTe)}

A distância detector-amostra trata-se de um parâmetro muito importante, pois é necessário ponderar entre a intensidade do feixe espalhando e a dispersão angular dos fótons que atingem o detector (seção 3.3.2.3c). Uma vez que, quanto maior a distância entre o detector e a amostra, menor será o ângulo sólido, ou seja, menor a dispersão angular, $\Delta \theta$, dos fótons coletados. Entretanto, o aumento da distancia detector-amostra causa uma diminuição da intensidade do feixe que atinge o detector, isto é, diminui o número de fótons adquiridos durante um determinado período de tempo, como mostra a Figura 3.7, a intensidade é inversamente proporcional à distância detector-amostra. 
Através da figura 3.7, nota-se que diminuindo apenas $4 \mathrm{~cm}$ da distância entre detector e amostra, ocorre um aumento na intensidade do feixe espalhado de quase 2,5 vezes. Assim sendo, a partir da determinação do ângulo nominal de espalhamento $\left(7^{\circ}\right)$, posicionou-se o detector de telureto de cádmio $(\mathrm{CdTe})$, o mais próximo possível da amostra, tomando-se o devido cuidado para que o detector "enxergue" toda a região irradiada na amostra e sem que este obstrua a passagem do feixe transmitido através da amostra, uma vez que, neste trabalho, foi construído um arranjo experimental com o objetivo de realizar as medidas dos feixes transmitido e espalhado pela amostra simultaneamente.

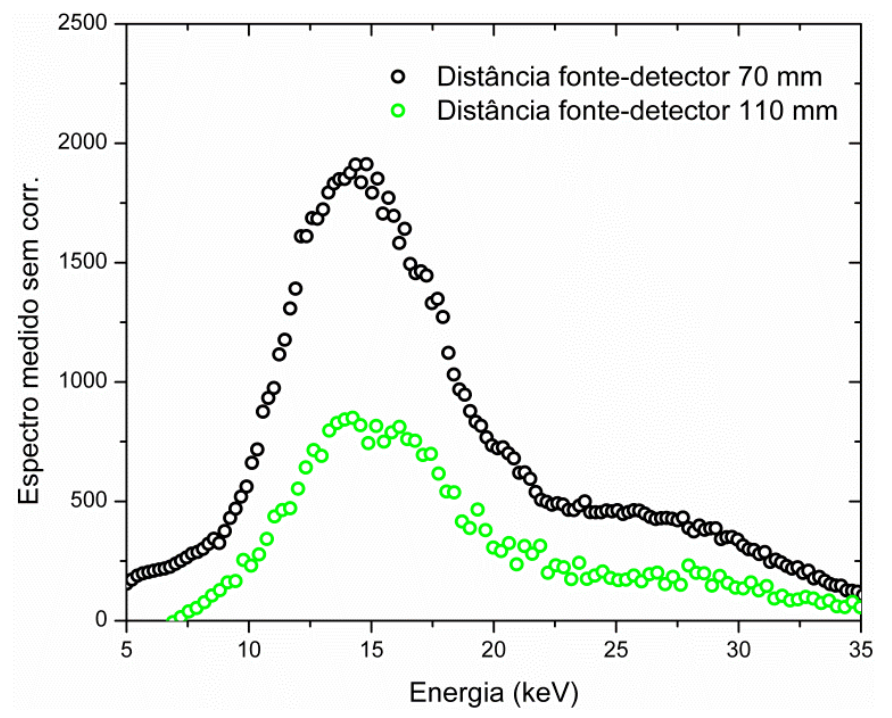

Figura 3.7: Comparação entre os espectros medidos pelo detector de CdTe a uma distância de 70mm da amostra e a uma distância de $110 \mathrm{~mm}$ da amostra.

\subsubsection{3c Avaliação do Borramento no perfil de espalhamento}

O borramento é o responsável pela limitação na definição das estruturas presentes no perfil de espalhamento, causando a não definição de alguns picos de espalhamento, bem como o seu alargamento, uma vez que, os perfis de espalhamento medidos são influenciados pela incerteza no momento transferido, $x\left(=\frac{E}{12,398} \operatorname{sen} \frac{\theta}{2}\right)$, dada por, $(\Delta x)^{2}=\left(\frac{\operatorname{sen} \theta / 2}{12,398}\right)^{2} \Delta E^{2}+\left(\frac{E}{12,398}\right)^{2}\left(\frac{\cos \theta / 2}{2}\right)^{2} \Delta \theta^{2}$, onde tem-se a influência de duas componentes: (i) resolução em energia do detector $(\Delta E)$ e (ii) dispersão angular do feixe espalhando $\left(\Delta \theta=\theta_{1}-\theta_{2}\right)$, sendo que, $\Delta \theta$, é a faixa de ângulo de espalhamento que o fóton 
incidente pode ser espalhado e coletado pelo detector, dependendo da posição no volume irradiado da amostra onde ocorra a interação (conforme definido na figura 3.8). Neste trabalho, utilizou-se um ângulo nominal fixo de $7^{\circ}$, e com as distâncias e sistema de colimação utilizado (tabela 3.2), definido na figura 3.8, obteve-se uma faixa de ângulo de espalhamento, $\Delta \theta$, igual a $1,63^{\circ}$. A figura 3.9 mostra $\Delta x$ em função de $x$. O incremento deste parâmetro com o momento transferido pode ser explicado, por um lado, como já é conhecido, pelo aumento da resolução em energia do detector com o incremento da energia, isto é, conforme aumenta-se o momento transferido (Luggar et al. 1996). Por outro lado, pela dependência do segundo termo com o momento transferido. A incerteza pode ser minimizada utilizando um detector com boa resolução em energia e/ou minimizando a dispersão angular do sistema.

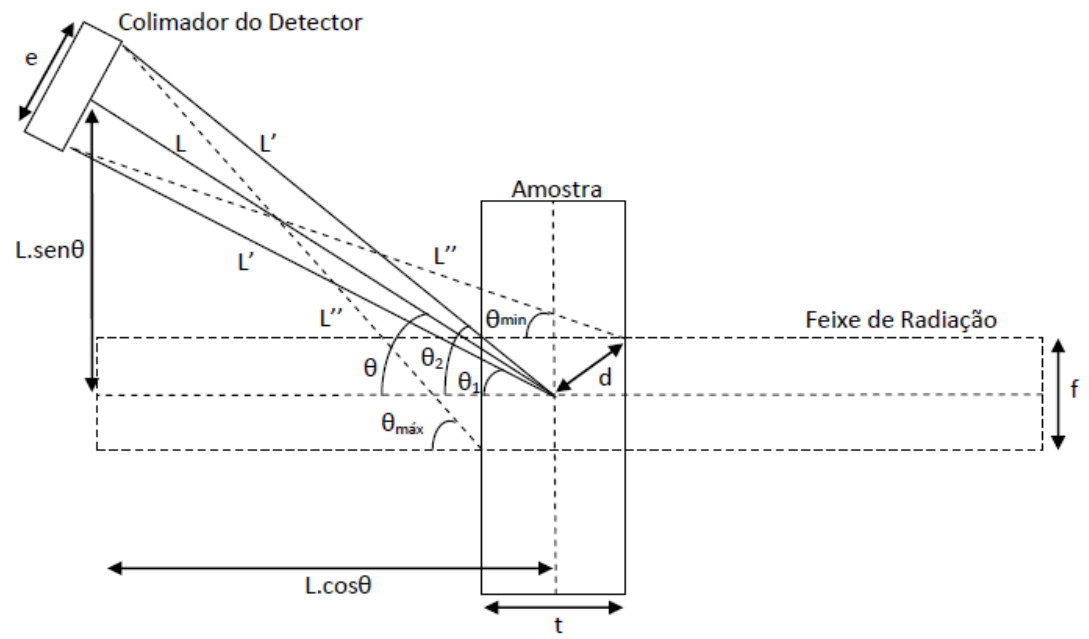

Figura 3.8: Esquema experimental do SRXDE e em destaque a região irradiada na amostra.

Tabela 3.2

Valores das variáveis independentes para a construção da geometria utilizada neste trabalho

\begin{tabular}{cc}
\hline $\begin{array}{c}\text { Variáveis } \\
\text { Independentes }\end{array}$ & Valores Nominais \\
\hline $\mathrm{L}(\mathrm{mm})$ & 88 \\
$\mathrm{t}(\mathrm{mm})$ & 4 \\
$\mathrm{f}(\mathrm{mm})$ & 1 \\
$\mathrm{e}(\mathrm{mm})$ & 2 \\
$\theta$ (graus) & 7 \\
\hline
\end{tabular}




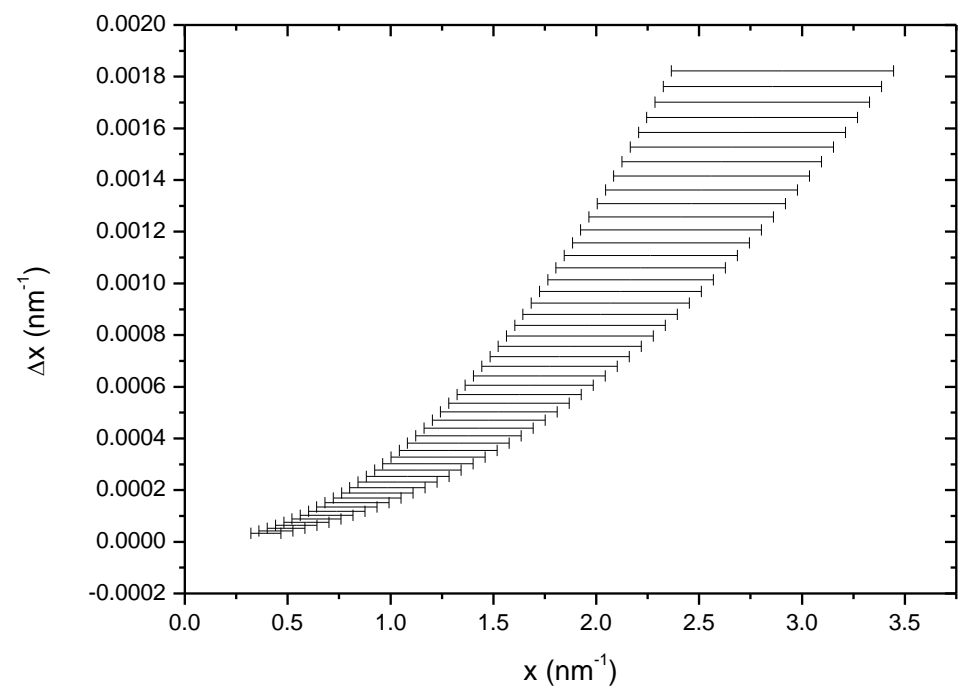

Figura 3.9: Resolução em momento transferido, $\Delta x$, em função do momento transferido $x$.

\subsection{Método para determinar o $\mu$}

O coeficiente de atenuação linear, $\mu(E)$, foi determinado através da geometria de feixe estreito, de acordo com a Lei de Lambert-Beer, pela medição da transmissão de um feixe polienergético de raios X através da amostra. Sendo que, $I_{0}(E)$ representa a contagem de fótons com energia $E$ no espectro de referência, e $I_{t}(E)$ representa a contagem no espectro atenuado pela amostra de espessura t, o coeficiente de atenuação linear médio para cada canal no espectro pode ser determinado usando-se (Tomal et al. 2010).

$\mu(E)=-\frac{1}{t} \ln \left(\frac{I_{t}(t)}{I_{0}(t)}\right)+\mu_{\mathrm{ar}}(\mathrm{E})$

Onde $\mu_{a r}(E)$ é o coeficiente de atenuação linear para o ar.

\subsection{Método para determinar o perfil de espalhamento}

A distribuição de energia do número de fótons espalhados detectados, $N(E)_{D}^{C d T e}$, possui contribuição de várias fontes de background (ar, porta-amostra e colimadores), sendo assim foi feita uma correção do espectro medido visando retirar essas contribuições de background. 


$$
N(E)_{s}^{\mathrm{cor}}=N(E)_{D}^{\mathrm{CdTe}}-B(E) T(E)
$$

Onde, $B(E)$, representa a medida do sinal de background (todas as contribuições) e $T(E)$ é um fator de transmissão apropriado a ser aplicado em $B(E)$, e pode ser calculado por $T(E)=e^{-\mu(E) t}$, onde $\mu(\mathrm{E})$ e $t$ são o coeficiente de atenuação linear e a espessura da amostra respectivamente (Poletti et al. 2002c).

Além disso, o espectro medido inclui espalhamento simples e múltiplo, entretanto, neste trabalho, a contribuição do espalhamento múltiplo foi desprezada, uma vez que, a espessura de cada amostra foi escolhida para minimizar sua probabilidade de ocorrência. O espalhamento simples é dado basicamente pelos fótons espalhamentos elasticamente, isto considerando a faixa de energia analisada, bem como, o ângulo nominal de espalhamento escolhido para posicionar o detector (7 graus). Isto pode ser evidenciado pela figura 3.10, onde observa-se que a probabilidade de ocorrência do espalhamento elástico é em média, na região de momento transferido observada, 8 vezes maior do que para o espalhamento inelástico. A figura 3.10 (a) apresenta as seções de choque diferenciais elástica e inelástica calculadas a partir dos dados para tecido muscular de Kosanetzky et al. 1987 em função do momento transferido. A figura 3.10 (b) mostra a razão da seção de choque diferencial elástica pela seção de choque diferencial inelástica em função do momento transferido.
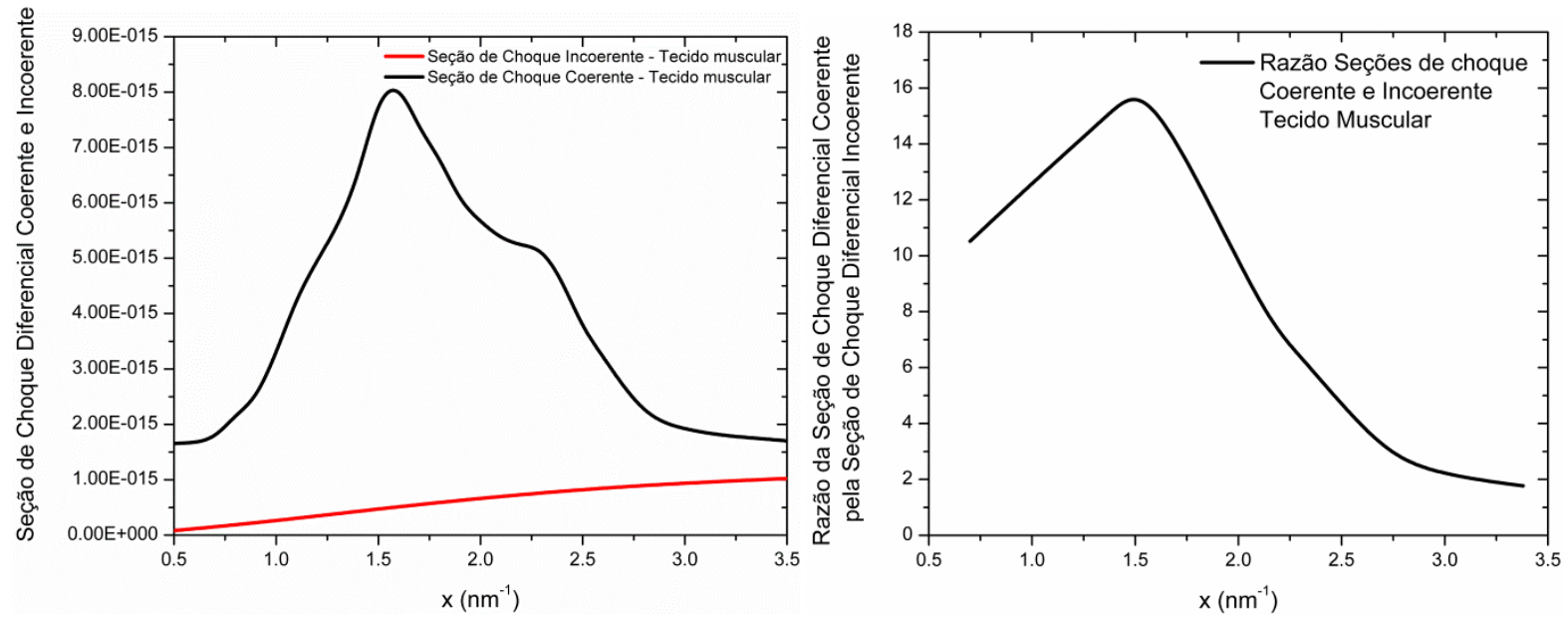

Figura 3.10: (a) Seções de choque diferenciais elástica e inelástica em função do momento transferido calculado a partir dos dados para tecido muscular de Kosanezky et al. 1987. (b) Razão da seção de choque diferencial coerente pela seção de choque diferencial incoerente em função do momento transferido. 
A distribuição de energia dos fótons espalhados (espalhamento simples), $N(E)_{S}^{c o r r}$, é relacionada ao perfil de espalhamento $\mu_{s}(x)\left(=\eta_{v}\left(d \sigma_{T h} / d \Omega\right) F^{2}(x)\right)$ por

$$
N(E)_{s}^{\mathrm{corr}}=\eta_{v} \frac{d \sigma_{T h}}{d \Omega} F^{2}(x) G(E) I(E)_{\theta=0} \varepsilon(E)_{\mathrm{CdTe}}
$$

Onde $\eta_{v}$ é o número de átomos ou moléculas por unidade de massa, $\left(d \sigma_{T h} / d \Omega\right)$ é a seção de choque Thomson, $F(x)$ o fator de forma, $x$ o momento transferido, $G(E)$ é um apropriado fator de transmissão geométrico, o qual pode ser calculado por $G(E)=\left[\frac{1 / t}{\mu(E)\left(1-\frac{1}{\cos \theta}\right)}\right]\left[e^{-\mu(E) t / \cos \theta}-e^{-\mu(E) t}\right], I(E)_{(\theta=0)}$ é a medida da distribuição de energia dos fótons incidentes (sem a amostra) corrigido pela eficiência do detector SDD $\left(\varepsilon(E)_{S D D}\right)$ e $\left(\varepsilon(E)_{C d T e}\right)$ é a eficiência do detector CdTe, a qual corrige a distribuição de energia dos fótons espalhados.

O perfil de espalhamento pode ser obtido imediatamente da equação (3.7),

$$
\mu_{s}(x)=\frac{N(E)_{s}^{\mathrm{corr}}}{G(E) I(E)_{\theta=0} \varepsilon(E)_{\mathrm{CdTe}}}
$$

Todos os fatores das equações (3.8-3.9) são unicamente dependentes da energia do fóton, uma vez que o ângulo de espalhamento é fixo.

\subsection{Validação da Metodologia}

O procedimento experimental utilizado neste trabalho para a medição das propriedades de atenuação e espalhamento dos tecidos humanos e materiais tecido-equivalentes foi validado a partir de medidas realizadas com poliacetato, nylon, e água líquida. E como já explicado, estes materiais foram escolhidos por possuírem coeficientes de atenuação linear similares aos dos tecidos mamários humanos estudados (White et al. 1980) e ainda por já terem tido suas propriedades de espalhamento estudadas em outros trabalhos presentes na literatura (Kosanetzky et al. 1987; Poletti et al. 2002b). 


\section{Validação da metodologia utilizada para calcular $\mu$}

Os valores experimentais do coeficiente de atenuação linear foram comparados com valores teóricos, calculados de acordo com a regra das misturas (Hubbell, 1982). Sendo que a os resultados experimentais obtidos para esses materiais comparados com os seus valores teóricos apresentaram diferenças de $6 \%$ para o poliacetato e de $7 \%$ para o nylon e água líquida. Deste modo, as diferenças obervadas são menores que as incertezas estatisticas (8\%) para todos os materiais. E como exemplo, a figura 3.11 apresenta os resultados obtidos neste trabalho para o poliacetato comparados com os valores teoricos (Berger et al. 2005), mostrando que o método utilizado é satisfatório.

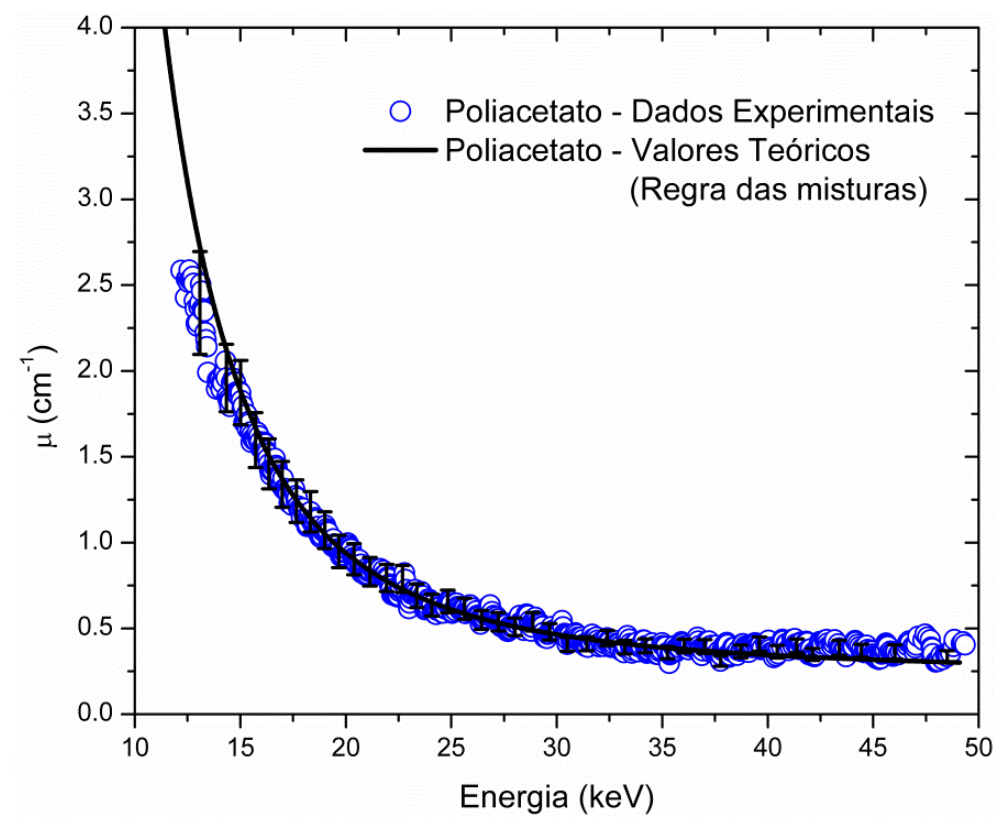

Figura 3.11: Validação do modelo experimental através da comparação do coeficiente de atenuação linear do poliacetato com os valores teóricos calculados a partir da regra das misturas.

\section{Validação da metodologia utilizada para construir os perfis de espalhamento}

Os dados experimentais obtidos para os perfis de espalhamento foram comparados com dados experimentais previamente publicados, uma vez que, não existem dados teóricos para os perfis de espalhamento disponíveis na literatura. Como exemplo, a figura 3.12 mostra os perfis de espalhamento normalizados para o nylon e água líquida comparados com os dados publicados por Kosanetzky et al. 
1987 e Poletti et al. 2002b. Nota-se a semelhança apresentada na forma dos perfis de espalhamento de ambos os materiais quando comparados com os dados previamente publicados. E ainda que as pequenas discrepâncias observadas entre a posição dos picos principais e largura a meia altura (LMA) foram de no máximo de $5 \%$, dentro da faixa de momento transferido analisado (até $3 \mathrm{~nm}^{-1}$ ), mostrando a boa adequação do método utilizado neste trabalho. Essas discrepâncias observadas podem ser explicadas pelo fato de que os dados previamente publicados por Kosanetzky et al. 1987 e Poletti et al. 2002b foram obtidos através de uma fonte monocromática de energia, possibilitando um menor borramento ou melhor definição do perfil de espalhamento. Porém, a vantagem de uma fonte polienergética, utilizada neste trabalho, está no fato de que o tempo de medição necessário é muito menor comparado com as técnicas anteriores.
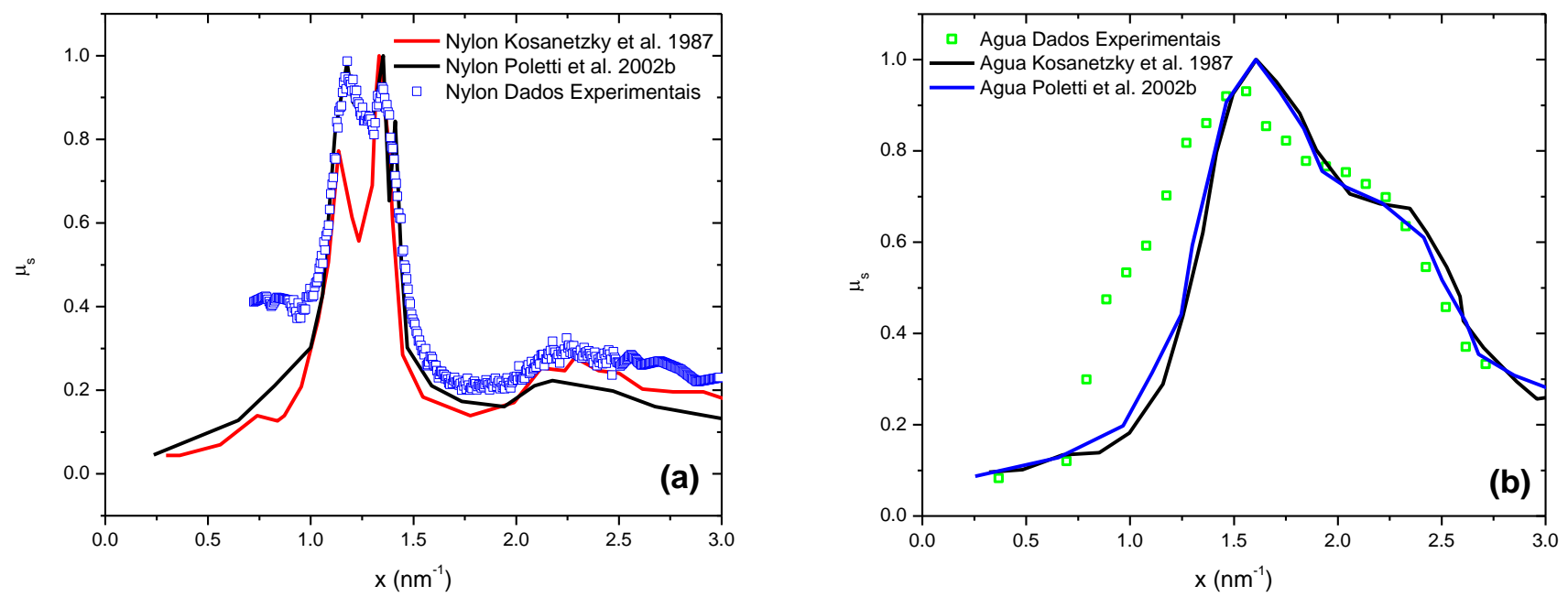

Figura 3.12: Comparação entre os perfis de espalhamento normalizados obtidos experimentalmente com os dados previamente publicados. (a) nylon (b) água líquida

\subsection{Escolha do melhor material tecido-equivalente}

\section{Critério de Escolha}

(i) Propriedades de Atenuação 
A escolha do melhor material tecido-equivalente, segundo suas propriedades de atenuação, teve como critério utilizado as diferenças apresentadas entre o coeficiente de atenuação linear experimental comparadas com o coeficiente de atenuação linear calculado teoricamente para os tecidos humano adiposo, muscular e ósseo. Sendo que estas diferenças devem ser menores que 5\%, como recomendado pelo ICRU (ICRU Report 44, 1989).

Para o calculo dos coeficientes de atenuação linear teóricos dos tecidos, suas composição e densidades foram extraídas do ICRU Report 44 (tabela 3.3), enquanto que o coeficiente de atenuação mássico para cada elemento foi obtido a partir do banco de dados do XCOM (Berger et al. 2005, XCOM: Photon cross section database version 1.3. Disponível: www.nist.gov/pml/data/xcom/index.cfm). Dessa forma, o coeficiente de atenuação mássico para cada tecido foi calculado. E a partir de suas densidades calcula-se os valores dos seus coeficientes de atenuação linear.

Tabela 3.3

Tecidos humano - Densidades e Composição

\begin{tabular}{ccc}
\hline Tecidos humano & Densidade $\left(\mathbf{g} / \mathbf{c m}^{3}\right)$ & Composição \\
\hline Tecido Adiposo $^{\text {a }}$ & 0,95 & $\mathrm{C}(0,598) ; \mathrm{H}(0,114) ;(0,278)$ \\
Tecido Muscular $^{\text {a }}$ & 1,05 & $\mathrm{C}(0,143) ; \mathrm{H}(0,102) ; \mathrm{O}(0,710)$ \\
Tecido Ósseo $^{\text {a }}$ & 1,92 & $\mathrm{C}(0,155) ; \mathrm{H}(0,034) ; \mathrm{O}(0,435) ; \mathrm{Ca}(0,225)$ \\
\hline
\end{tabular}

${ }^{\mathrm{a}}$ ICRU Report 44

(ii) Propriedades de Espalhamento

Em contrapartida, a escolha do melhor material tecido-equivalente, segundo suas proriedades de espalhamento, teve como critério utilizado a similaridade apresentada entre os perfis de espalhamento. Foram comparados os seguintes parâmetros: posição do pico principal e largura a meia altura (LMA). Os valores experimentais dos perfis de espalhamento dos materiais tecido-equivalentes foram comparados com dados experimantais prévios para tecidos humano adiposo, muscular e ósseo (Kosanetzky et al. 1987, Speller, 1999, Kidane et al. 1999). 


\section{CAPÍTULO 4}

\section{RESULTADOS E DISCUSSÕES}

\subsection{Propriedades de atenuação de materiais tecido-equivalentes}

A figura 4.1 apresenta os resultados obtidos através do coeficiente de atenuação linear para os materiais tecido-equivalentes: adiposo-equivalente, osso-equivalente, músculo-equivalente, água, nylon e PMMA. Comparados com os valores teóricos calculados para os tecidos adiposo, muscular e ósseo, usando a regra das misturas e composições e densidades definidas pelo ICRU (ICRU Report 44 1989). Como mostrado na figura 4.1 (a), em toda faixa de energia analisada, os dados para o material adiposo-equivalente apresentaram boa concordância com o coeficiente de atenuação linear para o tecido adiposo, uma vez que, observou-se para toda a faixa de energia analisada diferenças inferiores a 5\%. A figura 4.1(b) mostra que os valores do coeficiente de atenuação linear para a água e músculo-equivalente, são muito próximos daqueles valores de coeficiente de atenuação linear para o tecido muscular. Apresentando diferenças relativas inferiores a 5\%. A figura 4.1 (c), mostra os resultados para o osso-equivalente, o qual também apresenta diferenças relativas menores que 5\% com relação ao tecido ósseo, como recomendado pelo

ICRU (ICRU Report 44 1989). Dessa forma, pode-se concluir que, em termos das propriedades de atenuação, os materiais tecido-equivalentes atualmente comercializados que satisfazem os critérios do ICRU são: adiposo-equivalente (062A-11: CIRS, Norfolk, VA, USA), água, músculo-equivalente (062A10: Computerized Imaging Reference System Inc.- CIRS, Norfolk, VA, USA) e osso-equivalente (062A26: CIRS, Norfolk, VA, USA). 

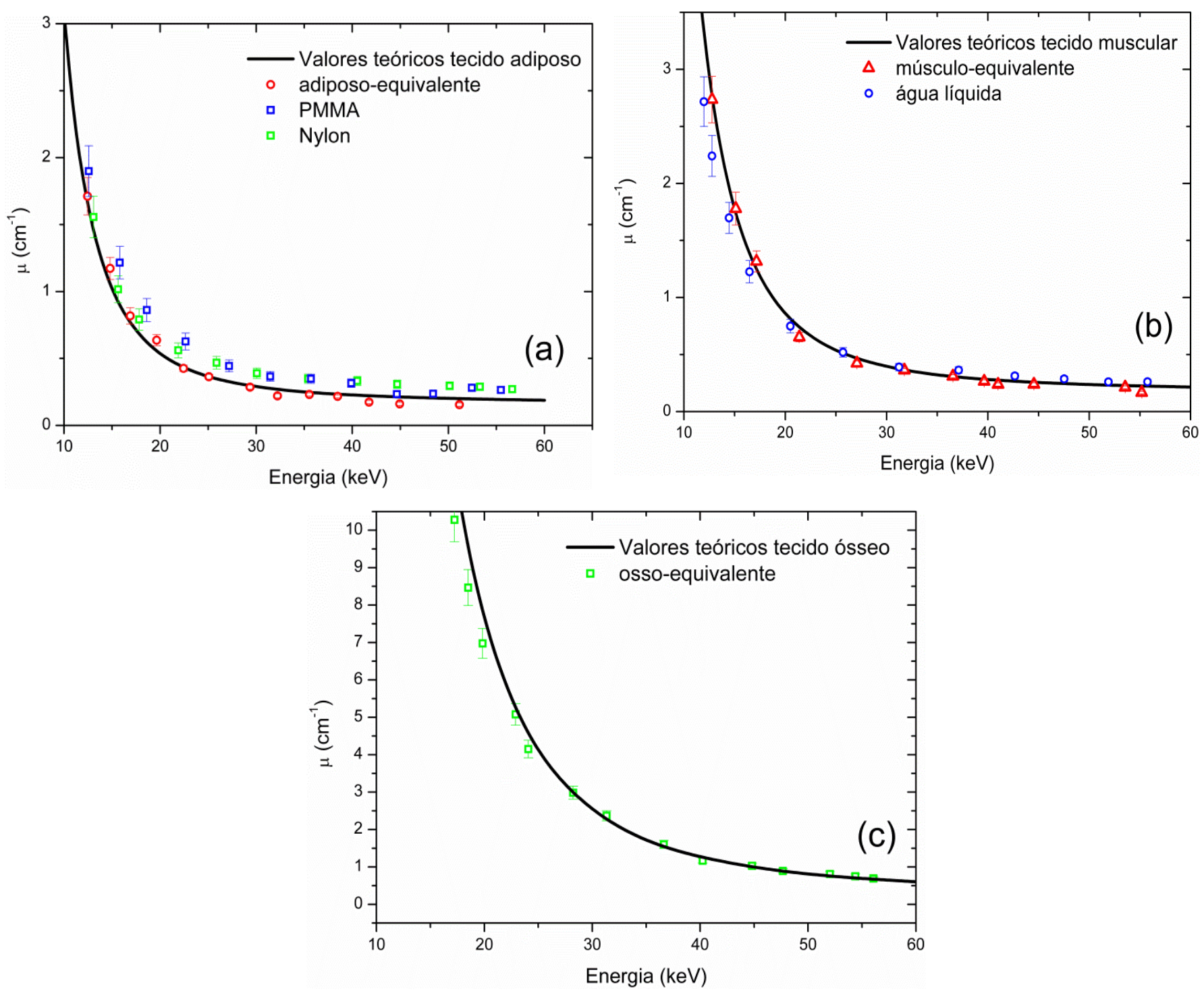

Figura 4.1: Comparação entre o coeficiente de atenuação linear do material tecido-equivalente determinado experimentalmente, e o tecido correspondente obtido teoricamente: (a) adiposo, (b) muscular e (c) ósseo.

\subsection{Propriedades de atenuação dos tecidos humanos}

A figura 4.2 mostra os resultados obtidos para o coeficiente de atenuação linear médio dos tecidos mamários humanos estudados neste trabalho: tecido normal (adiposo e fibroglandular) e tecido neoplásico benigno (fibroadenoma) e tecido neoplásico maligno (carcinoma). Comparados com resultados experimentais previamente publicados na literatura, Johns e Yaffe, 1987, Baldazzi et al. 2008 e Tomal et 
al. 2010. E ainda usando a regra das misturas e composições elementares para tecidos mamários normais dadas por Woodard e White 1986.
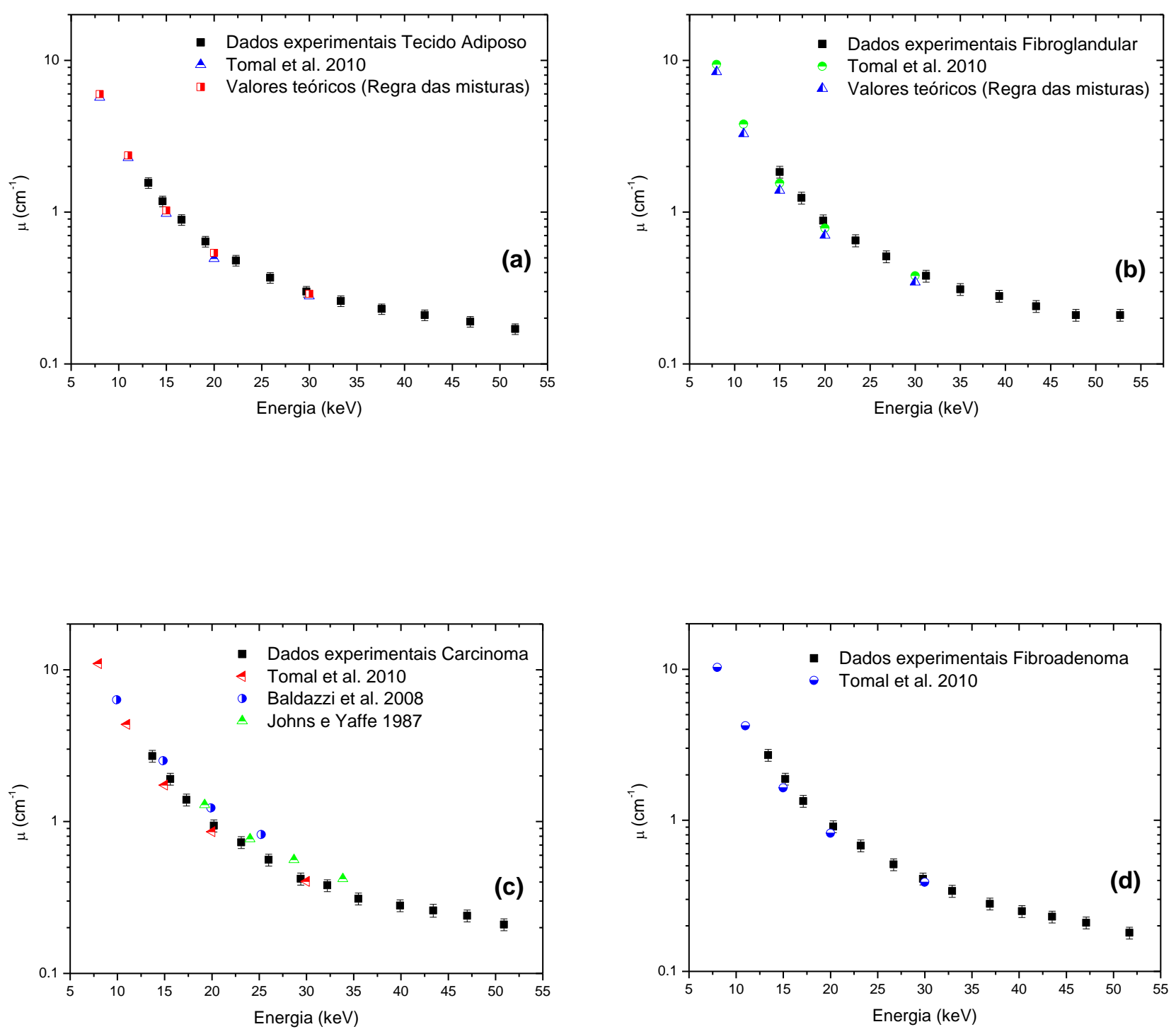

Figura 4.2: Comparação entre os resultados obtidos para o coeficiente de atenuação linear dos tecidos mamários e resultados previamente publicados na literatura: (a) adiposo, (b) fibroglandular, (c) carcinoma e (d) fibroadenoma.

Nota-se que os valores médios para o coeficiente de atenuação linear do tecido adiposo diferem significativamente daqueles obtidos para os outros grupos de tecidos analisados. 
Além disso, observa-se, pela figura 4.3, que o tecido normal fibroglandular possui coeficiente de atenuação linear similar aos apresentados pelos tecidos neoplásicos (carcinoma e fibroadenoma). Sendo que o grupo de tecido composto pelos fibroglandulares possui valores médios de coeficiente de atenuação linear ligeiramente menor que os grupos representados pelos fibroadenomas e carcinomas. Isso pode ser explicado pelo maior numero atômico efetivo dos tecidos neoplásicos (fibroadenoma e carcinoma) em comparação com os tecidos fibroglandulares (Antoniassi et al. 2010), como resultado do seu crescimento acelerado e aumento da concentração de vários elementos traços $(\mathrm{Ca}, \mathrm{Fe}, \mathrm{Cu}$ e $\mathrm{Zn})$ como mostrado por Silva et al. 2009. A diferença é menor a medida que aumenta-se a energia, sendo desprezível para energias acima de $35 \mathrm{keV}$.

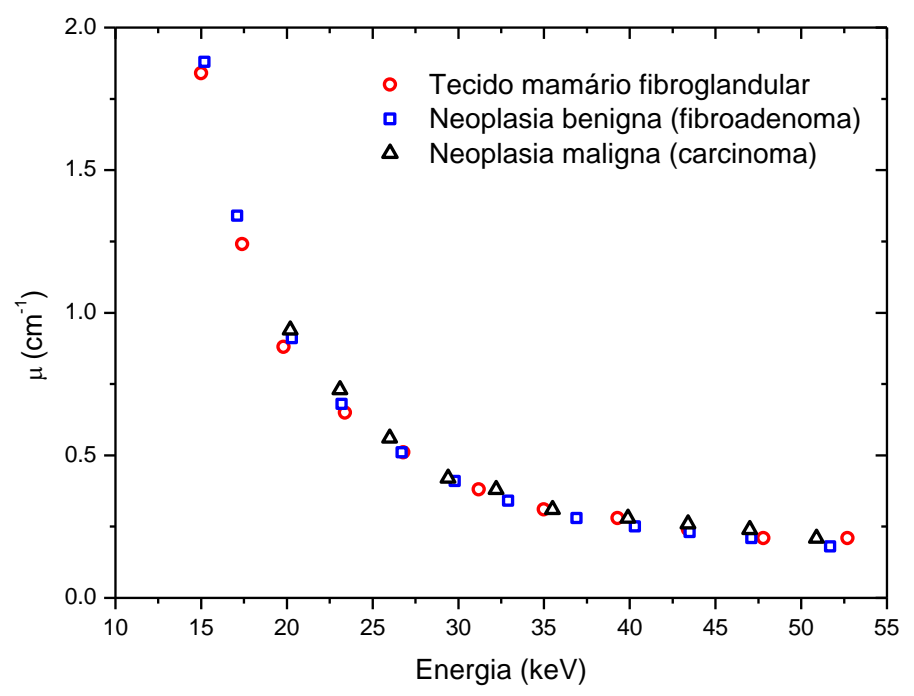

Figura 4.3: Comparação entre os resultados do coeficiente de atenuação linear do tecido normal fibroglandular e tecidos neoplásicos (fibroadenoma e carcinoma).

A variação observada nos resultados dos coeficientes de atenuação linear calculados $(9 \%$ para tecido adiposo, $7 \%$ tecido fibroglandular e $8 \%$ para as neoplasias), com relação aos valores médios dos tecidos analisados neste trabalho pode ser atribuída à variabilidade na composição das amostras de tecido mamário provenientes de diferentes pacientes. Sendo que essa variabilidade é relacionada a parâmetros 
externos: alimentação e ambiente. E também a parâmetros inerentes ao indivíduo: idade, genética e estado hormonal. Ou ainda, pela heterogeneidade da amostra analisada.

Através da comparação entre os resultados experimentais obtidos neste trabalho e os dados previamente publicados na literatura, Johns e Yaffe 1987, Baldazzi et al. 2008, Tomal et al. 2010 (experimentais) e com valores teóricos calculados de acordo com a regra das misturas, observa-se diferenças de no máximo 9\% com relação aos valores médios apresentados pelo tecido adiposo, $8 \%$ com relação aos tecidos fibroglandular e neoplásico maligno (carcinoma) e 5\% quando comparado com o tecido normal fibroglandular.

\subsection{Propriedades de espalhamento dos materiais tecido-equivalentes.}

A figura 4.4 mostra os perfis de espalhamento de alguns materiais tecido-equivalente a tecidos humanos (adiposo-equivalente, água e osso-equivalente) analisados neste trabalho (Geraldelli et al. 2012), comparados com alguns dados experimentais previamente publicados na literatura (Kosanetzky et al. 1987, Speller, 1999, Kidane et al. 1999).

Os diferentes formatos dos perfis de espalhamento, posição e intensidade dos picos são devido às correlações intermoleculares, ou seja, são devido à variação média do espaço intermolecular dos materiais equivalentes e/ou tecidos analisados (Poletti et al. 2002b). Nota-se pelos perfis de espalhamento, as características típicas de materiais amorfos da água e adiposo-equivalente, isto é, não há picos estreitos em seus perfis. Entretanto, o material osso-equivalente, apresenta características intermediárias entre materiais amorfos e cristalinos, já que, existem alguns picos mais estreitos em seu perfil de espalhamento, mostrando em sua composição, uma estrutura mais ordenada.

Os resultados experimentais para a água, material osso-equivalente, tecidos humano muscular e ósseo são apresentados na tabela 4.1 (Geraldelli et al. 2012). 


\section{Tabela 4.1}

Comparação da posição do pico principal, segundo pico e Largura a meia altura (LMA) para os tecidos muscular e ósseo, água e osso-equivalente.

\begin{tabular}{c|ccc}
\hline Material & Posição do Pico Principal $\left(\mathbf{n m}^{-\mathbf{I}}\right)$ & Posição do Segundo Pico $\left(\mathbf{n m}^{-\mathbf{I}}\right)$ & $\boldsymbol{F W H M ~}\left(\mathbf{n m}^{-1}\right)$ \\
\hline Osso-equivalente & 1,20 & 1,50 & 0,14 \\
Tecido ósseo & 1,42 & 1,75 & 0,26 \\
Tecido Muscular & 1,57 & --- & 0,65 \\
Água & 1,60 & --- & 0,67 \\
\hline
\end{tabular}

A figura 4.4 (a) mostra que o perfil de espalhamento do adiposo-equivalente apresentou grande semelhança com os dados medidos para tecido adiposo por Kidane et al. 1999, uma vez que, os perfis de espalhamento do adiposo-equivalente e tecido adiposo apresentam picos na mesma posição (em torno de $1,1 \mathrm{~nm}^{-1}$ ) e LMA com aproximadamente $0,28 \mathrm{~nm}^{-1}$. Na figura 4.4 (b) observa-se que a água pode ser um adequado material substituto para o tecido muscular, já que apresenta propriedades de espalhamento similares a este tecido, como mostrado previamente por Kosanetzky et al. 1987. A figura 4.4 (c) mostra os resultados obtidos para o material osso-equivalente em termos da intensidade normalizada para permitir a comparação com os dados previamente publicados (Speller, 1999).

Além disso, observa-se que embora os perfis de espalhamento do osso-equivalente e tecido ósseo apresentem formas similares, há uma discrepância de $14 \%$ na posição do pico principal. E que o perfil de espalhamento obtido para o osso-equivalente apresentou picos mais estreitos do que aqueles presentes no perfil de espalhamento do tecido ósseo. Isso pode ser explicado pela estrutura mais ordenada do material osso-equivalente comparado com o tecido ósseo. 

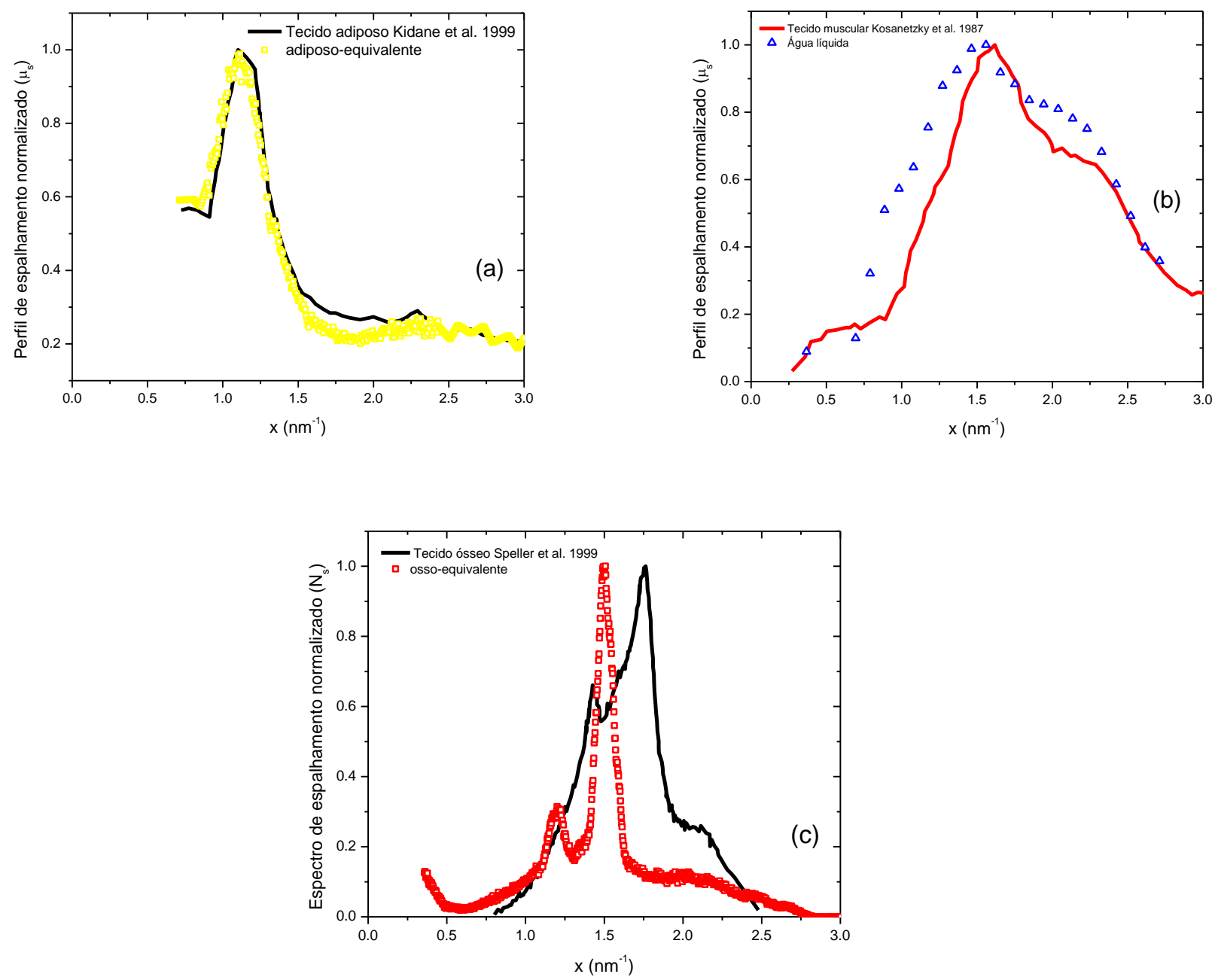

Figura 4.4: Comparação entre o perfil de espalhamento dos materiais tecido-equivalente e dos tecidos humanos. (a) adiposo-equivalente e tecido adiposo. (b) água e tecido muscular. (c) osso-equivalente e tecido ósseo (Geraldelli et al. 2012).

\subsection{Propriedades de espalhamento dos tecidos mamários humano}

A figura 4.5 apresenta para cada um dos grupos de tecidos analisados (adiposo, fibroglandular, carcinoma e fibroadenoma), o perfil de espalhamento médio obtido, os valores máximos e mínimos do perfil de espalhamento de cada um dos grupos, além de uma comparação com dados presentes na literatura. A comparação foi realizada tanto com trabalhos que utilizaram um sistema dispersivo em energia (Kidane et al. 1999, Ryan et. al. 2007), quanto com trabalhos que utilizaram um sistema dispersivo em ângulo 
(Tartari et al. 1997, Peplow e Verghese 1998, Poletti et al. 2002b, Oliveira et al. 2008, Conceição et al. 2010).
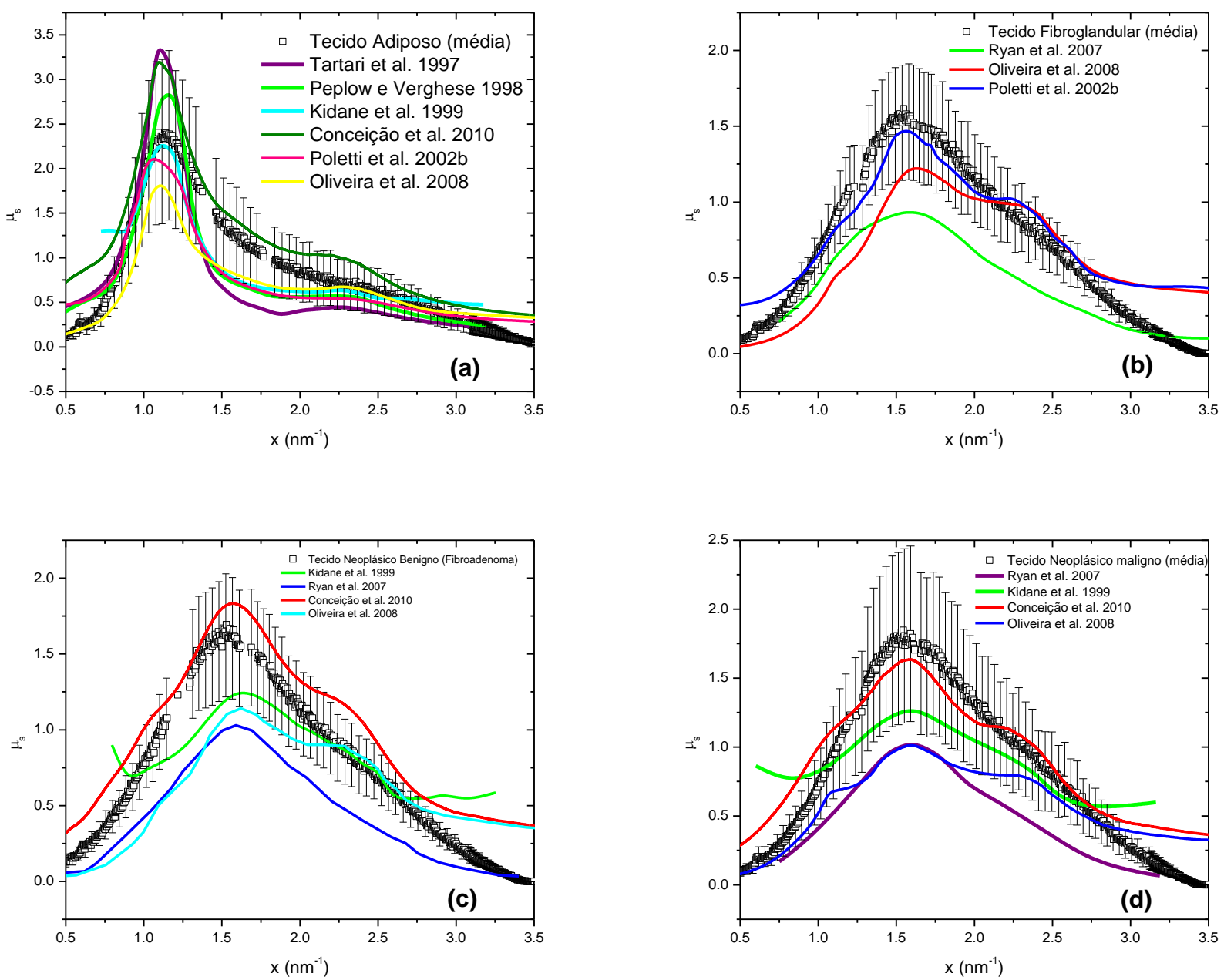

Figura 4.5: Comparação entre os perfis de espalhamento médio, máximo e mínimo para os tecidos analisados neste trabalho e os correspondentes dados previamente publicados na literatura. (a) adiposo (b) fibroglandular (c) carcinoma (d) fibroadenoma.

Observa-se da figura 4.5 que o perfil de espalhamento para os grupos de tecidos analisados possui poucos picos e com formato largo, típico de materiais amorfos. No perfil de espalhamento correspondente ao 
tecido adiposo nota-se a presença de um pico na posição de $\mathrm{x}=1,12 \mathrm{~nm}^{-1}$. Esse posicionamento está associado à cadeia carbônica de ácidos graxos, principal componente do tecido adiposo (Lide, 1996). Ou seja, na faixa de momento transferido analisada neste trabalho, pode-se concluir que os perfis de espalhamento medidos carregam informações sobre a estrutura relacionada aos ácidos graxos (Tartari et al. 1997). Em contrapartida, os perfis de espalhamento obtidos das amostras de tecidos fibroglandular, fibroadenoma e carcinoma, apresentam forma semelhantes, entretanto com diferenças em relação às intensidades. Observa-se que para os três grupos de tecidos analisados, é evidente a presença do pico principal na posição $\mathrm{x}=1,54 \mathrm{~nm}^{-1}$. Outro detalhe importante notado nestes perfis de espalhamento são suas similaridades com o perfil de espalhamento da água líquida. Isto pode ser explicado pela existência de água nesses tecidos, uma vez que, há uma grande quantidade de ácinos, os quais são compostos basicamente por água (Conceição, 2008). Justificando assim, o formato mais largo e menos intenso dos perfis de espalhamento desses tipos de tecidos quando comparados com os perfis do tecido adiposo.

A tabela 4.2 apresenta um resumo sobre os parâmetros analisados (posição do pico principal, intensidade média e LMA) extraídos dos perfis de espalhamento para cada grupo de tecido mamário analisados, bem como os dados extraídos dos perfis de espalhamento previamente publicados que foram usados nas comparações.

Conclui-se que com os resultados apresentados na tabela 4.2 e figura 4.5 que os parâmetros considerados neste trabalho, posição do pico, intensidade média e LMA, podem ser usados para diferenciação e caracterização dos diferentes tecidos mamários (Evans et al. 1991, Kidane et al. 1999, Griffiths et al. 2007, Elshemey et al. 2010).

Através da comparação de todos os grupos de tecidos analisados, com os respectivos dados publicados anteriormente, observa-se uma grande concordância com relação à posição do pico principal (diferenças inferiores a $2 \%$ para o tecido adiposo e de no máximo $6 \%$ para os demais tipos de tecidos). Porém, com relação à intensidade dos perfis nota-se, claramente, que existem diferenças. 
Tabela 4.2

Comparação dos parâmetros posição do pico principal, intensidade e LMA entre os perfis de espalhamentos obtidos neste trabalho e outros previamente publicados.

\begin{tabular}{|c|c|c|c|c|}
\hline $\begin{array}{c}\text { Descrição do } \\
\text { Tecido }\end{array}$ & Autor & $\begin{array}{l}\text { Posição do Pico } \\
\text { Principal }\left(\mathrm{nm}^{-1}\right)\end{array}$ & $\begin{array}{l}\text { Intensidade do } \\
\text { Pico Principal }\end{array}$ & $\operatorname{LMA}\left(\mathrm{nm}^{-1}\right)$ \\
\hline \multirow{7}{*}{ Adiposo } & Este trabalho & 1,12 & 2,37 & 0,33 \\
\hline & Tartari et al. 1997 & 1,10 & 3,33 & 0,29 \\
\hline & Peplow e Verghese 1998 & 1,14 & 2,81 & 0,28 \\
\hline & Kidane et al. 1999 & 1,12 & 2,25 & 0,28 \\
\hline & Poletti et al. 2002b & 1,12 & 2,09 & 0,39 \\
\hline & Oliveira et al. 2008 & 1,13 & 1,79 & 0,32 \\
\hline & Conceição et al. 2010 & 1,10 & 3,16 & 0,37 \\
\hline \multirow{4}{*}{ Fibroglandular } & Este trabalho & 1,54 & 1,61 & 0,72 \\
\hline & Ryan et al. 2007 & 1,54 & 0,93 & 0,85 \\
\hline & Poletti et al. 2002b & 1,59 & 1,47 & 1,02 \\
\hline & Oliveira et al. 2008 & 1,65 & 1,22 & 0,86 \\
\hline \multirow{5}{*}{ Fibroadenoma } & Este trabalho & 1,54 & 1,67 & 0,74 \\
\hline & Kidane et al. 1999 & 1,61 & 1,24 & 0,78 \\
\hline & Ryan et al. 2007 & 1,58 & 1,02 & 0,82 \\
\hline & Oliveira et al. 2008 & 1,55 & 1,13 & 0,87 \\
\hline & Conceição et al. 2010 & 1,55 & 1,83 & 0,50 \\
\hline \multirow{5}{*}{ Carcinoma } & Este trabalho & 1,54 & 1,85 & 0,72 \\
\hline & Kidane et al. 1999 & 1,54 & 1,26 & 0,84 \\
\hline & Ryan et al. 2007 & 1,59 & 1,02 & 0,78 \\
\hline & Oliveira et al. 2008 & 1,65 & 1,01 & 1,31 \\
\hline & Conceição et al.2010 & 1,56 & 1,63 & 0,50 \\
\hline
\end{tabular}

Estas diferenças podem ser explicadas, principalmente, pelas diferentes técnicas e amostragem utilizadas em cada trabalho. Kidane et al. 1999 e Ryan et. al. 2007, bem como este trabalho, utilizaram um sistema dispersivo em energia. Tartari et al. 1997, Peplow e Verghese 1998, Poletti et al. 2002b, Oliveira et al. 2008 e Conceição et al. 2010 utilizaram um sistema dispersivo em ângulo e feixes monocromáticos. E ainda, Tartari et al. 1997 e Peplow e Verghese 1998 usaram tecido adiposo animal. Nota-se através das comparações apresentadas (Figura 4.5 e Tabela 4.2) que a utilização de um sistema dispersivo em ângulo confere uma maior definição nos perfis de espalhamento, onde picos mais estreitos (até $10 \%$ mais estreitos) e mais intensos (até 30\% mais intensos) são observados quando comparados com os resultados de um trabalho realizado através de um sistema dispersivo em energia. Além disso, nota-se que um 
sistema dispersivo em ângulo possibilita resolver picos em momento transferido mais alto, o que não é observado nas medidas realizadas através de um sistema dispersivo em energia. Entretanto, a utilização de um sistema dispersivo em energia confere uma maior rapidez na coleta dos dados experimentais, uma vez que, o feixe polienergético empregado possibilita uma contagem de fótons superior em um determinado período de tempo quando comparado com um sistema dispersivo em ângulo.

\subsection{Potencialidades do Sistema de raios X Dispersivo em Energia}

\subsubsection{Análise de amostras heterogêneas}

O tecido biológico humano, geralmente apresenta composição heterogênea, ou seja, uma composição mista dos vários tipos de tecidos que compõem determinada estrutura do corpo humano. Sendo assim, quando estudado os perfis de espalhamento de determinado tecido, pode-se obter intensidades e posição de picos variados dependendo da composição da amostra. Deste modo, é útil fazer uma análise espacial em amostras heterogêneas, isto permite inclusive estudar regiões de transição entre tecidos normais e neoplásicos.

Para verificar a utilidade de nosso sistema em avaliar amostras heterogêneas foi medido o coeficiente de atenuação linear e o perfil de espalhamento de algumas destas amostras. A figura 4.6 mostra a imagem de uma das amostras estudas, sendo que os pontos A, B e C são os pontos onde aproximadamente incidiu-se a radiação durante as medições.

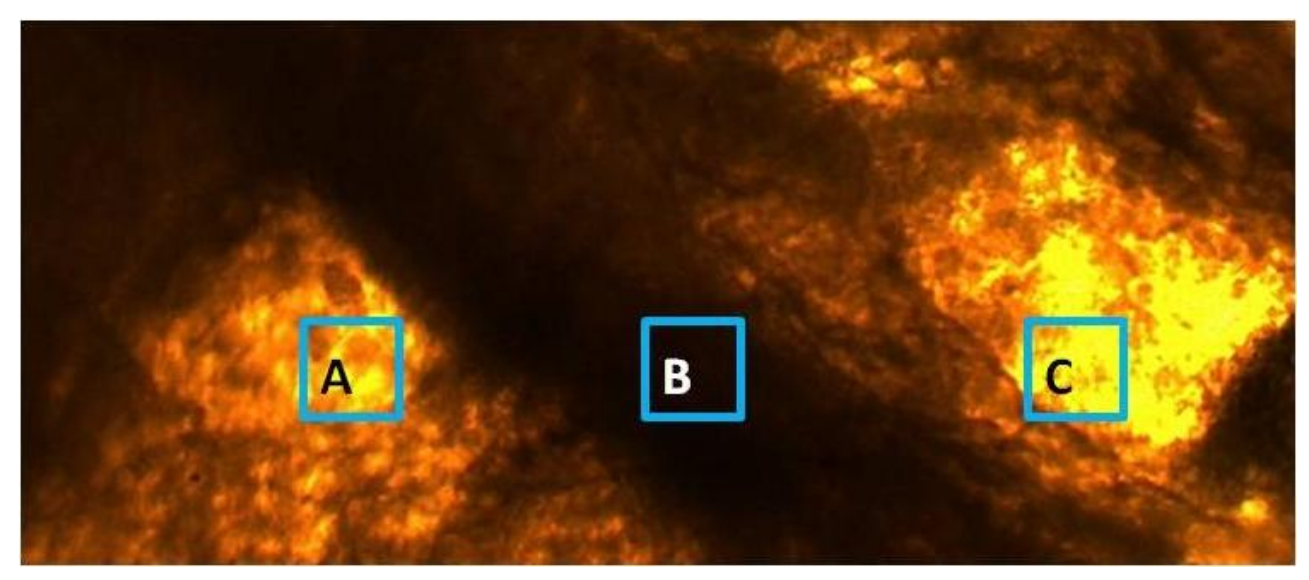

Figura 4.6: Imagem de uma amostra heterogênea de tecido mamário composto por tecido adiposo e fibroglandular. Os pontos A, B e C representados são os locais aproximados onde incidiu a radiação durante as medições. 
Os resultados obtidos através da varredura espacial (nos pontos A, B e C) para o perfil de espalhamento e coeficiente de atenuação linear são apresentados na figura 4.7. Nota-se que é possível fazer através dos resultados obtidos uma diferenciação entre os tipos de tecidos encontrados na amostra. Uma vez que, para os pontos onde há um predomínio de tecido adiposo (A e C) observa-se que os picos estão na mesma posição $\left(1,13 \mathrm{~nm}^{-1}\right)$ e possuem intensidades iguais. Em contrapartida, o ponto onde há predomínio de tecido fibroglandular (B) está posicionado em $1,55 \mathrm{~nm}^{-1} \mathrm{e}$ possui intensidade $35 \%$ menor em relação aos pontos A e C. As propriedades de atenuação também podem ser analisadas com a varredura da amostra. Os pontos A e C (predomínio de tecido adiposo) apresentaram coeficiente de atenuação linear similares, com diferença máxima de 5\%. Entretanto quando comparados com o coeficiente de atenuação para o ponto C, diferenças de até $40 \%$ são observadas.

Nota-se assim a eficácia do método desenvolvido neste trabalho, uma vez que, é possível fazer a diferenciação e caracterização de tecidos presentes em uma amostra heterogênea, a qual se assemelha muito as condições normais encontradas no interior do corpo humano.
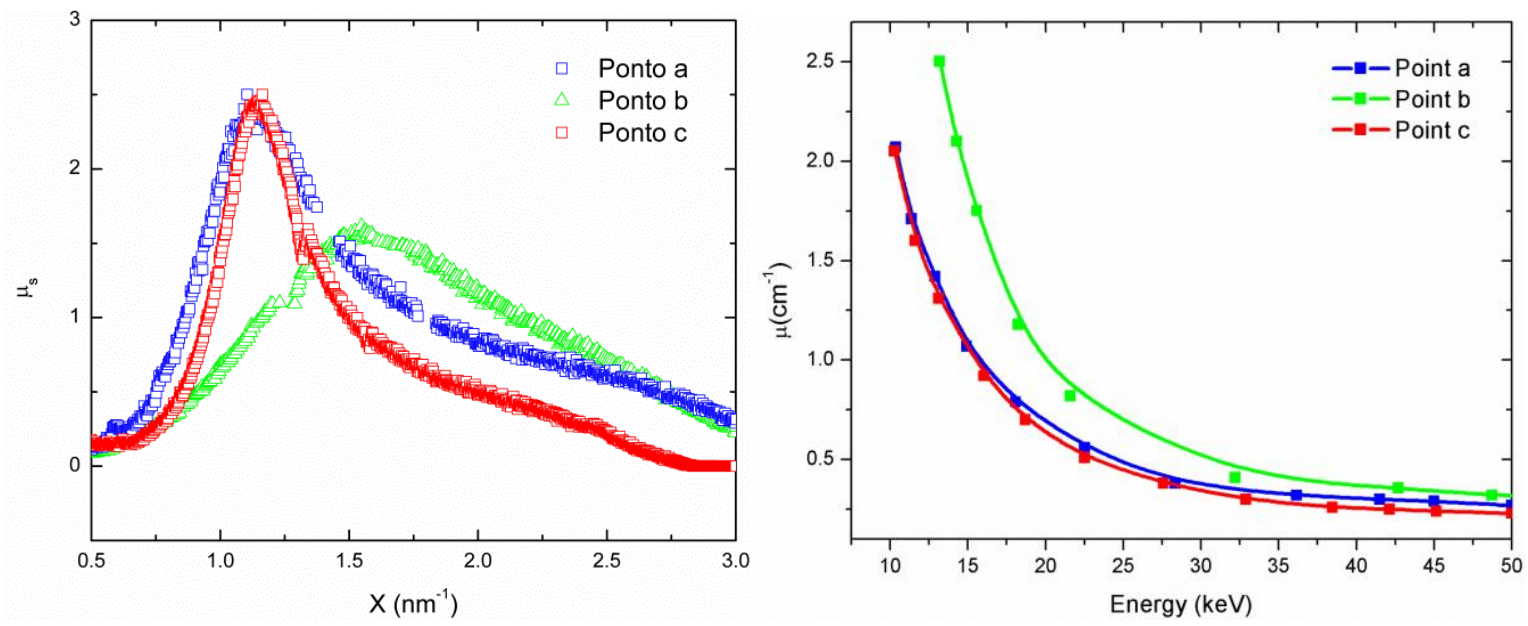

Figura 4.7: Comparação dos coeficientes de atenuação linear e dos perfis de espalhamento entre os três pontos estudados durante o processo de varredura de uma amostra heterogênea de tecido mamário composta por tecido adiposo e fibroglandular.

\subsubsection{Ferramenta de Diagnóstico.}

Observa-se pela figura 4.8 (a) que a principal faixa de energia para diferenciação e caracterização dos tecidos, por meio de suas propriedades de atenuação ocorre entre 10 e $35 \mathrm{keV}$, uma vez que, diferenças de 
até $40 \%$ são observadas entre tecido adiposo e os demais tipos de tecido. As diferenças entre os coeficientes de atenuação linear dos tecidos vão diminuindo à medida que a energia do feixe incidente aumenta. Sendo que para energias acima de $35 \mathrm{keV}$ as diferenças são inferiores a $10 \%$ entre todos os tipos de tecidos analisados neste trabalho.

Pela figura 4.8 (b) nota-se que cada um dos grupos de tecido mamários estudados apresenta um perfil de espalhamento característico e que a principal região para diferenciação e caracterização desses tecidos, através de suas propriedades de espalhamento, ocorre entre $0,8 \mathrm{~nm}^{-1}$ e $2,0 \mathrm{~nm}^{-1}$. Sendo que a diferença notável ocorre entre o tecido normal adiposo e os demais tecidos (fibroglandular, fibroadenoma e carcinoma), principalmente devido à presença do pico do adiposo.
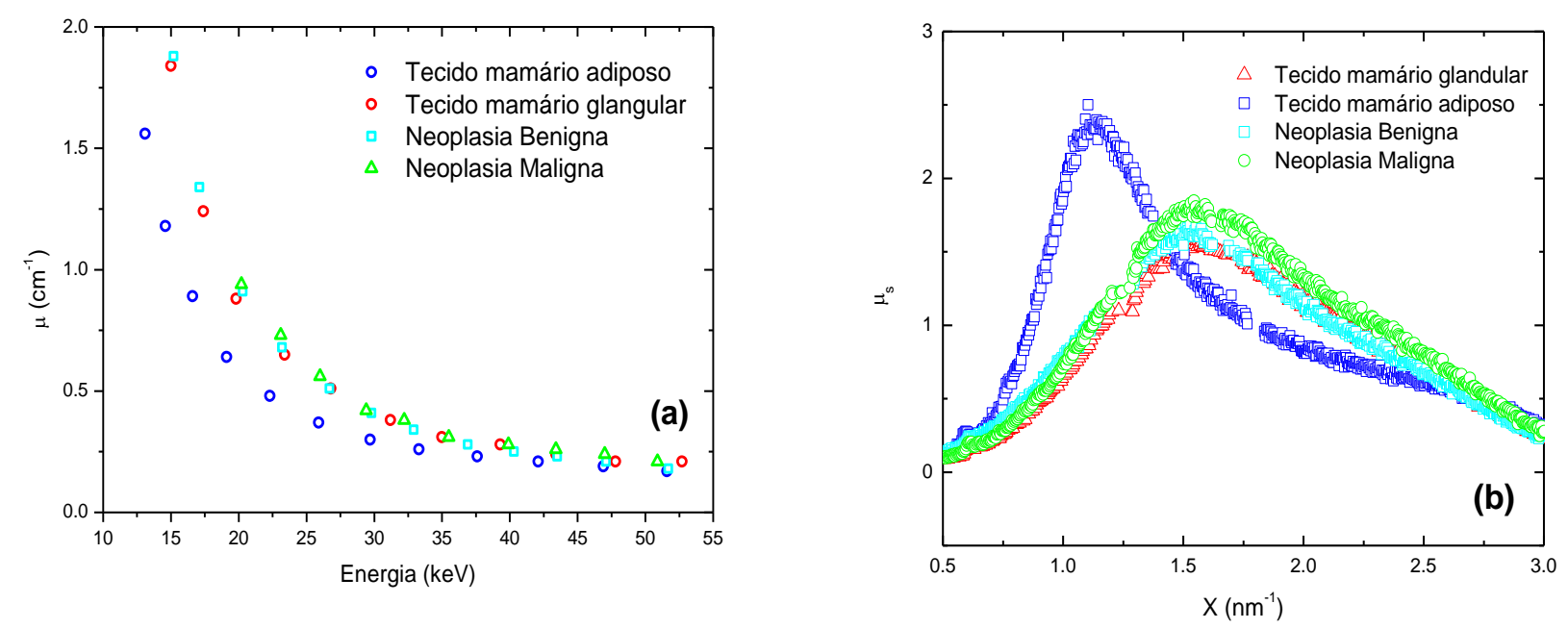

Figura 4.8: Resultados médios para o coeficiente de atenuação linear e perfil de espalhamento para cada tipo de tecido. (a) coeficiente de atenuação linear. (b) perfil de espalhamento. 


\section{CAPÍTULO 5}

\section{CONCLUSÕES E PERSPECTIVAS}

\subsection{Conclusões}

\subsubsection{Sobre o método de medição simultânea das propriedades de atenuação e espalhamento dos}

tecidos e tecido-equivalentes.

Este trabalho apresenta um método experimental para obtenção simultânea das propriedades de atenuação e espalhamento de amostras de tecidos mamários e materiais tecido-equivalente.

O procedimento de otimização da espessura das amostras associado com o sistema de colimação dos detectores permitiu, respectivamente, minimizar a variância nas medidas dos coeficientes de atenuação linear, bem como o número de fótons espalhados chegando ao detector (Tomal, 2007).

A metodologia empregada neste trabalho gerou incertezas inferiores a $8 \%$ nos dados finais de coeficientes de atenuação linear.

Por outro lado, com relação ao procedimento utilizado para obtenção dos perfis de espalhamento, notouse que, em geral, as incertezas experimentais na contagem de fótons e correções variaram entre 5\% e 15\%. Sendo que estas incertezas estão relacionadas com a dispersão angular dos fótons espalhados e a resolução em energia do detector.

Os procedimentos experimentais para obtenção dos coeficientes de atenuação linear foram validados através da comparação entre o coeficiente de atenuação linear experimental do poliacetato, nylon e água líquida com seu coeficiente de atenuação linear calculados teoricamente pela regra das misturas.

Os procedimentos de correção dos perfis de espalhamento foram validados através da comparação dos perfis de espalhamento obtidos para o nylon e água líquida com dados previamente publicados na literatura (Kosanetzky et al. 1987, Poletti et al. 2002b), sendo que as diferenças observadas nos parâmetros analisados (posição do pico principal, LMA e intensidade) foram menores que 5\%, dentro das incertezas experimentais, significando que a metodologia utilizada foi satisfatória. 


\subsubsection{Sobre os resultados obtidos para os materiais tecido-equivalentes quanto suas propriedades}

\section{de atenuação e espalhamento.}

A partir dos resultados, pode-se concluir que análises cuidadosas para a escolha de um material tecidoequivalente são necessárias, inclusive análises das propriedades de atenuação e espalhamento desses materiais, uma vez que, os materiais tecido-equivalentes comercializados atualmente possuem propriedades muito diferentes. Neste trabalho, foi utilizado três parâmetros para caracterizar os materiais tecido-equivalentes analisados: (i) coeficiente de atenuação linear experimental; (ii) posição do pico principal do perfil de espalhamento e (iii) LMA (do pico mais intenso do perfil de espalhamento).

Deste modo, considerando as analises preliminares realizadas neste trabalho foi possível identificar que dentre os materiais tecido-equivalente comercializados, o adiposo-equivalente (062A-11: CIRS, Norfolk, VA, USA) pode ser um bom substituto para o tecido adiposo, enquanto que a água líquida e o material músculo-equivalente (062A-10: Computerized Imaging Reference System Inc.- CIRS, Norfolk, VA, USA) são bons simuladores para o tecido muscular. Finalmente, o tecido ósseo pode ser simulado adequadamente pelo material osso-equivalente (062A-26: CIRS, Norfolk, VA, USA) (Geraldelli et al. 2012).

\subsubsection{Sobre os resultados obtidos para os tecidos mamários humanos quanto suas propriedades de atenuação e espalhamento.}

Os mesmos três parâmetros já empregados nas análises dos materiais tecido-equivalente, foram utilizados para as análises dos tecidos mamários, incluindo a intensidade dos picos no perfil de espalhamento.

Os resultados obtidos mostraram que é possível fazer a diferenciação e caracterização dos tecidos mamários através de suas propriedades de atenuação e espalhamento. Por meio de suas propriedades de atenuação, a principal faixa de energia para caracterização dos tecidos esta entre 10 e $35 \mathrm{keV}$, uma vez que, diferenças de até $40 \%$ são observadas entre o coeficiente de atenuação linear do tecido adiposo e dos demais tecidos estudados (fibroglandular, fibroadenoma e carcinoma). 
Através das propriedades de espalhamento dos tecidos, a principal região de caracterização ocorre no intervalo de momento transferido entre $0,8 \mathrm{~nm}^{-1}$ e $2,0 \mathrm{~nm}^{-1}$. O tecido adiposo apresentou picos em $1,12 \mathrm{~nm}^{-1}$, que está relacionado ao espalhamento construtivo de moléculas de ácidos graxos (Conceição 2008). Entretanto, para os tecidos normais fibroglandulares e neoplásicos (benigno e maligno), o pico

principal ocorre em $1,54 \mathrm{~nm}^{-1}$, correspondente a grande quantidade de água nestes tecidos (Conceição 2008).

Deste modo, pode-se concluir através dos resultados obtidos, que o método desenvolvido neste trabalho é adequado para analisar simultaneamente as propriedades de atenuação e espalhamento dos tecidos mamários humanos. Sendo assim, o método é útil para o diagnóstico de anomalias mamárias, uma vez que, é capaz de diferenciar e caracterizar tecidos mamários humanos normais e alterados, bem como, permite estudar regiões de transição em amostras heterogêneas.

\subsection{Perspectivas Futuras}

A partir dos resultados obtidos neste trabalho, abrem-se as seguintes perspectivas:

- Medir os perfis de espalhamento e coeficientes de atenuação linear simultaneamente e englobar a maioria das neoplasias mamárias encontradas clinicamente, não analisadas neste trabalho.

- Realizar medidas em um intervalo maior de momento transferido. Para verificar se existem estruturas ainda não identificadas no que diz respeito às propriedades de espalhamento dos tecidos.

- Uma vez que, já foi identificada a utilidade do método desenvolvido neste trabalho, se faz necessário construir um arranjo experimental mais adequado, que sofra menos influências externas e que possibilite a medição em menor tempo e com melhor resolução em energia. 


\section{APÊNDICE}

\section{A - Aprovação do Comitê de Ética em Pesquisa}

Universidade de São Paulo

Faculdade de Filosofia, Ciências e Letras de Ribeirão Preto

"Campus" de Ribeirão Preto

Of.CEtP/FFCLRP.USP/083/-jsI

Ribeirão Preto, 01 de julho de 2011.

Prezado Pesquisador,

Comunicamos a V. Sa. que o trabalho intitulado "IDENTIFICAÇÃo DE NEOPLASIAS MAMÁRIAS ATRAVÉS DE MEDIDAS DE PERFIS DE ESPALHAMENTO OBTIDOS COM FEIXES POLIENERGÉTICOS" foi analisado pelo Comitê de Ética em Pesquisa da FFCLRP-USP, em sua $97^{\text {a }}$ Reunião, realizada em 30.06.11, e enquadrado na categoria: APROVADO, de acordo com o Processo CEP-FFCLRP n 582/2011 2011.1.1468.59.9.

Atenciosamente,

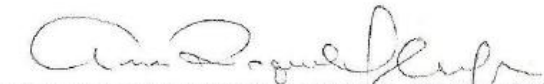

Prof. ${ }^{\text {a }}$ Dr. ${ }^{\text {a }}$ ANA RAQUEL LUCATO CIANFLONE Coordenadora

Ao Senhor

Wender Geraldelli

Recebi o\{s) original(is)

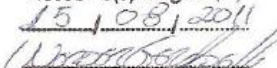

Mestrando do Programa de Pós-Graduação em Fisica aplicada à Medicina e Biologia da FFCLRP - USP

Com cópia para o orientador:

Prof. Dr. Martin Eduardo Poletti

Recebi ofs. original(is)

Departamento de Física da FFCLRP - USP

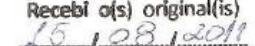

CEP - Comitê de Etica em Pesquisa da FFCLRP

Fone: (16) 3602-4681

Fax: (16) 3633-2660 (direto) ou 3633-5015

Avenida Bandeirantes, 3900 - bloco 1 - 14040-901 - Ribeirăo Preto - SP - Brasi

Armenare 


\section{REFERÊNCIAS BOBLIOGRÁFICAS}

AL-BAHRI, J., SPYROU, N.M. Photon linear attenuation coefficients and water content of normal and pathological breast tissues. Applied Radiation and Isotopes 47 (8): 777-784, 1996.

ANDERSON, D.W. Absorption of Ionizing radiation, University Park Press, 1984.

ANTONIASSI, M., CONCEIÇÃO, A.L., POLETTI, M.E., Study of effective atomic number of breast tissues determined using the elastic to inelastic scattering ratio, Nuclear Instruments and Methods, 2010.

ATTIX, F.H. Introduction of radiation physics and radiation dosimetry. A Wiley. Interscience Publication, Madison, Wisconsin, 1986.

BALDAZZI, G., ROSSI, P., MASETTI, S., TURCO, A., FIASCHETTI, M., LANCONELLI, N., BIANCHINI, D., ROMA, L., NICOLETTI, G., LOLLINI, P., Characterization of biological tissues using X-ray attenuation data, NSS 08 IEEE Conference Record, 4798-4802, 2008.

BARNES, G.T. Contrast and Scatter in X-ray Imaging. RadioGraphics 11: 307, 1991.

BERGER M.J., HUBBELL J.H. XCOM: Photon Cross Section Database. Web Version 1.2. National Institute of Standards and Technology, Gaithersburg, MD 20899, USA, August 1999. Disponível em: http://physics.nist.gov/xcom. Originalmente publicado como NBSIR 87-3597, XCOM: Photon Cross Section on a Personal Computer (1987).

BERGER, M.J., HUBBELL, J.H., SELTZER, S.M., CHANG, J., COURSEY, J.S., SUKUMAR, R., ZUCKER, D.S., 'XCOM: Photon cross section database version 1.3', Disponível em: http://www.nist.gov/pml/data/xcom/index.cfm, 2005.

CARROLL, F.E., WATERS, J.W., ANDREWS, W.W., PRICE, R.R., PICKENS, D.R., WILLCOTT, R. TOMPKINS, P., ROOS, C., PAGE, D., REED, G., UEDA, A., BAIN, R., WANG, P., BASSINGER, M. Attenuation of monochromatic X-ray by normal and abnormal breast tissues. Investigative radiology 29 (3): 266-272, 1994.

CASTRO, C. R. F., BARROSO, R. C., LOPES, R. T. Scattering signatures for some human tissue using synchrotron radiation. X-Ray Spectrometry 34 (6): 477-480, 2005.

CHAN, H.P., DOI, K. Energy and Angular Dependence od X-ray Absorption and its Effect on Radiographic Response in Screen-Film System, Physics in Medicine and Biology, 28, 565-579, 1983.

CHANGIZI, V., OGHABIAN, M.A., SPELLER, R., SARKAR, S., KHERADMOND, A.A., Aplication of small angle X-ray scattering (SAXS) for differentiation between normal cancerous breast tissue, International Journal of Medical Sciences, 2(3): 118-121, 2005. 
CHAPARIAN, A., OGHABIAN, M.A., CHANGIZI, V., FARQUHARSON, M.J., The optimization of an energy-dispersive X-ray diffraction system for potential clinical application, Applied Radiation and Isotopes, 68: 2237-2245, 2010.

COTRAN, R. S., KUMAR, V., ROBBINS, S. L. Pathologic Basis of Disease. W. B. Saunders Company, 4 ed., 1989.

CONCEIÇÃO, A.L.C. Caracterização estrutural de tecidos mamários normais e neoplásicos através de espalhamento de raios X. (Dissertação). Ribeirão Preto: Faculdade de Filosofia Ciências e Letras de Ribeirão Preto, Universidade de São Paulo; 2008.

CONCEIÇÃO, A.L.C., POLETTI, M.E., Identification of molecular structures of normal and pathological human breast tissue using synchrotron radiation, AIP Conference Proceedings, 1266, 72-77, 2010.

CONNER, A.L., ATWATER, H.F., PLASSMANN, E.L., Gamma-ray Attenuation Coefficients Measurements, Physical Review A, 1(3), 539-544, 1970.

CUNHA, D. M., OLIVEIRA, O. R., PÉREZ, C. A. E POLETTI, M. E. X-ray scattering profiles of some normal and malignant human breast tissue. X-ray Spectrometry 35: 370-374, 2006.

CUNHA, D. M., TOMAL, A., POLETTI, M. E. Evaluation of scatter-to-primary ratio, grid performance and normalized average glandular dose in mammography by Monte Carlo simulation including interference and energy broadening effects. Physics in Medicine and Biology. 55: 4335-4346, 2010.

DÂNGElO, J. G. e FATTINI, C. A. Anatomia Humana Sistêmica e Segmentar. $2^{\text {a }}$ Ed. São Paulo, Rio de Janeiro, Ribeirão Preto, Belo Horizonte. Atheneu, 2003.

ELSHEMEY, W.M., DESOUKY, O.S., FEKRY, M.M., TALAAT, S.M., ELSAYED, A.A., The diagnostic capability of X-ray scattering parameters for the characterization of breast cancer, Medical Physics, 37(8), 4257-4265, 2010.

EVANS, S.H., BRADLEY, D., DANCE, D.R., BATERMAN, J.E. e JONES, C.H., Measurements of small-angle photon scattering for some breast tissues and tissue substitute materials. Physics in Medicine and Biology 36 (1): 7-18, 1991.

GERAlDELli, W., TOMAL, A., POLETTI, M.E., Characterization of tissue-equivalent material through measurements of the linear attenuation coefficient and scattering profiles obtained with polyenergetic beams, IEEE Transaction on Nuclear Science, 2012 (Submetido para publicação).

GRIFFITHS, J. A., ROYLE, G. J., HANBY, A. M., HORROCKS, J. A.,BOHNDIEK, S. E. e SPELLER, R. D. Correlation of energy dispersive diffraction signatures and microCT of small breast tissue samples with pathological analysis. Physics in Medicine and Biology 52: 61516164, 2007. 
HUBBELL, J.H., VEIGELE, E.A., BRIGGS, E.A., BROWN, D.T., CROMER, D.T., HOWERTON, R.J., Atomic Form Factor, Incoherent Scattering Functions and Photon Scattering Cross Section, Journal od Physics and Chemical Reference Data, 4(3), 471-538, 1975.

HUBBELL, J.H., Photon Mass Attenuation and Energy-absorption Coefficients from $1 \mathrm{keV}$ to 20MeV, International Journal of Applied Radiation and Isotopes 33, 1269-1290, 1982.

ICRU 44, Tissue Substitutes in Radiation Dosimetry and Measurement, International Commission on Radiation Units and Measurements (Bethesda, MD), 1989.

INSTITUTO NACIONAL DE CÂNCER, Ministério da Saúde. Estimativa 2015: Incidência de Câncer no Brasil. Rio de Janeiro: INCA, 2011.

JACKSON, D. F., HAWKES, D. J. X-ray attenuation coefficients of elements and mixtures. Physics Reports 70 (3): 169-233, 1981.

JOHnS, H. E., CUnNInghaM, J. R. The Physics of Radiology. Springfield: Charles C. Thomas, 1983.

JOHNS, P. C., YAFFE, M. J. Coherent Scatter in Diagnostic Radiology. Medical Physics 10(1): 40-50, 1983.

JOHNS, P. C., YAFFE, M. J. X-ray characterization of normal and neoplastic breast tissues. Physics in Medicine and Biology 32 (6): 675-695, 1987.

KIDANE, G., SPELLER, R.D., ROYLE, G.J., HANBTY, A.M. X-ray scatter signatures for normal and neoplastic breast tissues. Physics in Medicine and Biology 44: 1791-1802, 1999.

KOCH, H. A., AZEVEDO, C. M., BOECHAT, A. L., CANELLA, E., DUARTE, D. L., PERREIRA, R., KALAF, J. M., LAMAS, J., LOPES, E. R., MARANHÃO, N., PEIXOTO, J. E., SANTOS, R. P. Radiologia da mama - qualidade em mamografia. Radiologia Brasileira 29 (5): 257-269, 1996.

KOSANETZKY, J., KNOERR, B., HARDING, G., NEITZEL, U. X-ray diffraction measurements of some plastic materials and body tissues. Medical Physics 14 (4): 526-532, 1987.

LIDE, R.D., CRC Handbook of Chemistry and Physics $77^{\text {th }}$ edn (Boca Raton, FL: Chemical Rubber Company), 1996.

LUGGAR, R.D., HORROCKS, J.A., SPELLER, R.D., LACEY, R.J., Determination of the geometric blurring of an energy dispersive X-ray diffraction (EDXRD) system and its use in the simulation of experimentally derived diffraction profile, Nuclear Instruments and Methods in Physics Research A, 383, 610-618, 1996.

MAUTNER, B. D., SCHIMIDT, K. V., BRENNAN, M. B. New diagnostic techniques and treatments for early breast cancer. Seminars in Oncology Nursing 16 (3): 185-196, 2000. 
MICHAELSON, J. S., SILVERSTEIN, M., WYATT, J., WEBER, G., MOORE, R., HALPERN, E., KOPANS, D. B., HUGHES, K. Predicting the survival of patients with breast carcinoma using tumor size. Cancer 95 (4): 713-723, 2002.

MIDGLEY, S. Energy resolution for accurate measurements of the X-ray linear attenuation coefficient. Radiation Physics and Chemistry 75: 936-944, 2006.

MIYAJIMA, S., Thin CdTe detector in diagnostic x-ray spectroscopy, Medical Physics, 30 (5), 771-777, 2003.

MUSHLIN, A. I., KOUIDES, R. W. e SHAPIRO, D. E. Estimating the accuracy of screening mammography A meta-analysis. American Journal of Preventive Medicine 14 (2): 143-153, 1998.

NETTER, F.H., Atlas de anatomia humana. $3^{\text {a }}$ Ed. University of Rochester School of Medicine and Dentistry Rochester New York: Artmed, 2004.

OLIVEIRA, O. R., CONCEIÇÃO, A. L. C., CUNHA, D. M., POLETTI, M. E., PELÁ, C. A. Identification of neoplasias of breast tissue using a commercial powder diffractometer. Journal of Radiation Research 49: 527-532, 2008.

PANI, S., COOK, E.J., HORROCKS, J.A., JONES, J.L., SPELLER, R.D., Characterization of breast tissue using energy-dispersive X-ray diffraction computed tomography, Applied Radiation and Isotopes, 68: 1980-1987, 2010.

PEPLOW, D.E. and VERGHESE, K. Measured molecular coherent scattering form factors of animal tissues, plastics and human breast tissue. Physics in Medicine and Biology 43: 24312452, 1998.

POLETTI M.E. Análise do contraste, dose e desempenho de uma grade relacionada ao espalhamento na imagem mamográfica. Dissertação de Mestrado. Universidade de São Paulo, Faculdade de Filosofia Ciências e Letras de Ribeirão Preto. Ribeirão Preto, 1997.

POLETTI M.E, Estudo de Espalhamento de Fótons $(6,94,17,44,59,54 \mathrm{keV})$ em Tecidos Mamários, Materiais Equivalentes e sua influência em Mamografia, 2001, 91f. Tese (Doutorado em Física) - Instituto de Física, Universidade Federal do Rio de Janeiro, rio de Janeiro, 2001.

POLETTI, M.E., GONÇALVES, O., MAZZARO, I., Coherent and Incoherent scattering 17.44 and $6.93 \mathrm{keV} \mathrm{X}$-ray photon scattered from biological and biological-equivalent sample:

Characterization of tissue, X-Ray Spectrometry, 31 (6), 57-61, 2002a.

POLETTI, M.E., GONÇALVES, O.D. e MAZZARO, I. X-Ray Scattering from Human Breast Tissues and Breast-Equivalent Materials. Physics in Medicine and Biology 47: 47-63, 2002b.

POLETTI, M.E., GONÇALVES, O.D., SCHECHTER, H., MAZZARO, I., Precise evaluation os elastic differential scattering cross-section and their uncertainties in X-ray scattering 
experiments. Nuclear Instruments and Methods in Physics Research B, 187, 437-446, 2002c.

POLETTI, M.E., GONÇALVES, O.D., MAZZARO, I., Measurements of X-ray scatter signatures for some tissue-equivalent materials. Nuclear Instruments and Methods in Physics Research B, 213, 595-598, 2004.

RYAN, E. A. e FARQUHARSON, M. J. Breast tissue classification using scattering measurements and multivariate data analysis. Physics in Medicine and Biology 52: 6679-6696, 2007.

SCHMITT, F. Mama. In: COTRAN, R. S., KUMAR, V., COLLINS, S. L. Robbins: Patologia estrutural e funcional. Rio de Janeiro: Guanabara Koogan, 2000.

SEIDMAN, H., STELLMAN, S. D. e MUSHINSKI, M. H. A different perspective on breast cancer risk factors: some implications of the nonattributable risk. CA: A Cancer Journal for Clinicians 32 (5): 301-313, 1982.

SILVA, M.P., TOMAL, A., PEREZ, C.A., RIBEIRO-SILVA, A., POLETTI, M.E., Determination of $\mathrm{Ca}, \mathrm{Fe}, \mathrm{Cu}$ and $\mathrm{Zn}$ and their correlations in breast cancer and normal adjacent tissues, X-ray Spectrometry, 38(2), 103-111, 2009.

SPRAWLS, P. Physical Principles of Medical Imaging. 2nd Edition. Medical Physics Publishing, Madison, Wisconsin, 1995.

SOUHAMI, R. e TOBIAS, J. Cancer and Its Management (London: Blackwell Science Ltd), 1998.

SPELLER, R.D., HORROCKS, J.A., Photon Scattering: A "New" Source of Information in Medicine and Biology?, Physics in Medicine and Biology, 36(1), 1-6, 1991.

SPELLER, R. D. Tissue analysis using X-ray scattering. X-ray Spectrometry 28: 244-250, 1999.

STEWART, B.W., KLEIHUES, P., World Cancer Report. IARC Nonserial Publication. World Health Organization. International Agency for Research Cancer, 2003.

TABAR, L., FABERBERG, C. J. G., GAD, A., ET AL. Reduction in mortality from breast cancer after mass screening with mammography. Randomized trial from the Breast Cancer Screening Working Group of the Swedish national Board of Health and Welfare. Lancet, 325 (8433): 829-832, 1985.

TARTARI, A., CASNATI, E., BONIFAZZI, C., BARALDI, C. Molecular differential cross sections for x-ray coherent scattering in fat and polymethyl methacrylate. Physics in Medicine and Biology 42: 2551-2560, 1997a. 
TOMAL, A. Medidas experimentais dos coeficientes de atenuação de tecidos mamários e sua influência no contraste e dose mamográfica. Dissertação de mestrado. Faculdade de Filosofia Ciencias e Letras de Ribeirão Preto, Universidade de São Paulo, Ribeirão Preto 2007.

TOMAL, A., MAZARRO, I., KAKUNO, E.M., POLETTI, M.E., Experimental Determination of linear attenuation coefficient of normal, benign and malignant breast tissues, Radiation Measurements, 45(9), 1055-1059, 2010.

TOMAL, A., CUNHA, D.M., ANTONIASSI, M., POLETTI, M.E., Response functions of $\mathrm{Si}(\mathrm{Li}), \mathrm{SDD}$ and CdTe detectors for mammographic X-ray spectroscopy, Applied Radiation and Isotopes, 70(7), 1355-1359, 2012.

WHITE, D.R., PEAPLE, L.H. J., CROSBY, T.J. Measured Attenuation at Low Photon Energies (9.88-59.32 keV) for 44 Materials and Tissues. Radiation Research 84: 239-252, 1980.

WOODARD, H.Q., WHITE, D.R., The composition of body tissues, British Journal of Radiology, 59 (705), 1209-1219, 1986. 